\title{
Characterization of Organophosphate Pesticides \\ in Urine and Home Environment Dust \\ in an Agricultural Community
}

\section{Catherine Marie Tamaro}

\author{
A thesis \\ submitted in partial fulfillment of the \\ requirements for the degree of \\ Master of Science \\ University of Washington \\ 2016 \\ Committee: \\ Elaine M. Faustman \\ Thomas M. Burbacher \\ William C. Griffith
}

Program Authorized to Offer Degree:

Environmental Toxicology

Department of Environmental and Occupational Health Sciences

School of Public Health 
(C) Copyright 2016

Catherine Marie Tamaro 
University of Washington

\begin{abstract}
Characterization of Organophosphate Pesticides

in Urine and Home Environment Dust in an Agricultural Community
\end{abstract}

Catherine Marie Tamaro

Chair of the Supervisory Committee:

Professor Elaine M. Faustman

Department of Environmental and Occupational Health Sciences

Background: Organophosphorus insecticides (OPs) are used widely on crops to control agricultural pests, but they can have harmful effects on humans.

Farmworkers have higher exposure to OP pesticides than non-farmworkers living in the same community, due to their occupational exposure, and there is concern that farmworker children may in turn have higher exposure to OPs than nonfarmworker children.

Methods: A community-based participatory research strategy was used in the Lower Yakima Valley of Washington state to identify 100 farmworker (FW) and 100 non-farmworker (NFW) adults, each with a referent child between the ages of 2 and 6 years. Farmworker adults worked as thinners or harvesters in apple or pear orchards. Parents and children participated in three data collection periods over 
the course of a year: three urine samples within five days were provided for each collection period, homes were vacuumed once each collection period, and vehicles were vacuumed once during two of the collection periods. Urine was evaluated for the dialkylphosphate metabolites (DAP) characteristic of OP exposure, and dust was evaluated for intact OP residues.

Results: The geometric mean (GM) concentrations in house dust of four commonly used agricultural OPs were higher in farmworker households than in non-farmworker households across all three agricultural seasons. Farmworker households had higher GM concentrations of OPs in vehicle dust than nonfarmworker households in thinning season, when OPs are applied most intensively. The GM concentration of urinary DAP was higher for children in farmworker households than non-farmworker households during thinning season. Regression analysis of log-transformed variables found a positive correlation between children's urinary DAP and OP residues in house dust in thinning season.

Conclusions: GM concentrations of OPs in house dust and vehicle dust were higher in farmworker households than non-farmworker households, especially in thinning season. OPs in house dust were a significant factor affecting the children's urinary DAP levels. This relationship was most significant during thinning season and was not observed during the dormant, non-spray season. These results provide support for the occupational take-home pathway of exposure by which children are exposed to agricultural pesticides used in the workplace. 


\section{LIST OF FIGURES}

$\underline{\text { Page }}$

Figure 1: Urinary Metabolites of Organophosphate Pesticides

Figure 2: Limits of Detection of Dialklyphosphate Metabolites of Organophosphate Pesticides in Urine

Figure 3: Limits of Detection of Intact Organophosphate Pesticides in Dust Samples

Figure 4: Geometric Mean Concentration and 95\% Confidence Interval of the Five Most Abundant OPs Detected in Dust Samples

Figure 5: Geometric Mean Concentration and 95\% Confidence Interval of DMAP and DEP+DETP Urinary Metabolites

Figure 6: Regression of Log of DMAP Urinary Metabolites vs. Log of Dimethyl OP Residues in House Dust by Agricultural Season

Figure 6: Regression of Log of DEP+DETP Urinary Metabolites vs. Log of Diethyl OP Residues in House Dust by Agricultural Season 


\section{LIST OF TABLES}

Table 1: Estimated Annual Agricultural Pesticide Use in Metric Tons for Benton and Yakima Counties

Table 2: Concentrations and Detection Frequencies of Five Organophosphate Pesticides Most Commonly Detected In House Dust in Lower Yakima Valley

Table 3: Concentrations and Detection Frequencies of Five Organophosphate Pesticides Most Commonly Detected In Vehicle Dust in Lower Yakima Valley

Table 4A: Concentrations and Detection Frequencies of Six Dialkyphosphate Metabolites Detected in Child Urine in Lower Yakima Valley

Table 4B: Concentrations and Detection Frequencies of Six Dialkyphosphate Metabolites Detected in Adult Urine in Lower Yakima Valley

Table 5A: Proportions and Detection Frequencies of Three Dimethylalkylphosphate Metabolites Detected in Child Urine in Lower Yakima Valley

Table 5B: Proportions and Detection Frequencies of Three Dimethylalkylphosphate Metabolites Detected in Adult Urine in Lower Yakima Valley

Table 6A: Concentrations of Six Dialkylphosphate Metabolites Detected in Child Urine in United States and Lower Yakima Valley

Table 6B: Concentrations of Six Dialkylphosphate Metabolites Detected in Adult Urine in United States and Lower Yakima Valley 


\section{LIST OF ABBREVIATIONS}

DAP - dialkyl phosphate metabolites $=\sum(\mathrm{DEAP}+\mathrm{DMAP})$

DEAP - diethyl alkylphosphate metabolites $=\sum($ DEP + DETP + DEDTP $)$

DEP - diethyl phosphate

DETP - diethyl thiophosphate

DEDTP - diethyl dithiophosphate

DMAP - dimethyl alkylphosphate metabolites $=\sum(\mathrm{DMP}+\mathrm{DMTP}+\mathrm{DMDTP})$

DMP - dimethyl phosphate

DMTP - dimethyl thiophosphate

DMDTP - dimethyl dithiophosphate

GM - geometric mean

OP - organophosphate pesticide 


\section{INTRODUCTION}

Agriculture is an important component of the economy of the state of Washington. Apples are the state's most valuable cash crop while pears rank consistently in the top ten [1]. The state ranks first in the U.S. in acreage planted and in harvest value for both apples and pears [1], [2]. Organophosphate insecticides (OPs) are applied seasonally to apple and pear (pome fruit) orchards in order to control insects such as the codling moth (Cydia pomenella) that would otherwise damage or destroy the fruit. Following the passage of the Food Quality Protection Act of 1996, the U.S. Environmental Protection Agency (EPA) initiated a regulatory review of OPs [3], [4]. In 2000, EPA restricted use of chlorpyrifos (trade name Dursban; Chemical Abstracts Service (CAS) No. 2921-88-2) on apples to dormant and pre-bloom seasons, and the interval between time of application and re-entry into the site of agricultural application was lengthened [5], [6]. In 2001, EPA announced a multi-year phase-out of all uses of azinphos-methyl (AZM; trade name Guthion; CAS No. 86-50-0) [7]. In that same year, EPA announced a five-year phase-out of the use of phosmet (trade name Imidan; CAS No. 732-11-6) on pome and other tree fruits [8], and the agency prohibited sales of diazinon (CAS No. 33341-5) for residential uses after 2004 [9]. Nonetheless, as shown in Table 1, approved agricultural uses led to the application in 2005 of approximately 86 metric tons of azinphos-methyl, 66 metric tons of chlorpyrifos, 39 metric tons of phosmet, 5 metric tons of malathion (CAS No. 121-75-5), and 1 metric ton of diazinon in Yakima and Benton counties, where the lower Yakima Valley (Valley) is located [10], [11]. 
OPs inhibit the enzyme acetylcholinesterase, which results in an accumulation of the neurotransmitter acetylcholine at the neuronal synapses [12], [13]. There is some epidemiologic evidence that long-term occupational exposure may result in neurological disorders, including depression, neuropathy, and dementia [14]-[18]. Farmworkers can be exposed to OPs as part of their regular work [19], [20]. There is evidence that farmworkers' families, including their children, can be exposed to OPs that were utilized in the workplace, via the occupational take-home pathway [21]-[24]. Children have unique exposures and vulnerabilities to environmental hazards, due to their higher exposure on a body-weight basis, their immature metabolic pathways, and their rapid growth and development [25]-[27]. Although the health effects of OPs in adults are well characterized, less is known about the long-term effects of chronic exposure in young children [28]. Examination of four U.S. birth cohorts suggests that prenatal exposure to OPs is linked to developmental delays and behavioral problems (concerning attention, short-term memory, executive function, and motor skills) in childhood [29]. Research into the effects of post-natal OP exposure on child neurodevelopment has produced inconsistent conclusions, but there is some evidence that low-level chronic OP exposure can lead to behavioral problems in children [30].

Since 1999 the University of Washington's Center for Child Environmental Health Risks Research (CHC) has followed a community-based participatory research strategy in the Valley to assess and reduce pesticide exposure among children of local farmworkers, most of whom are of Hispanic origin [21], [31]. CHC's previous studies indicated that young children two to six years of age were exposed 
to pesticides through a take-home pathway and that farmworkers who worked in pome fruit crops, as well as their children, were more heavily exposed to pesticides than farmworkers working in non-pome crops such as cherries and peaches [32], [33]. In response to that work, the Community Advisory Board (CAB) recommended a new project examining potential seasonal differences in exposure pathways important for children of agricultural workers compared to children of non-agricultural workers. Specifically, the CAB wanted to know if farmworkers and their children have higher levels of OP exposure than non-farmworkers and their children living in the same communities. In addition, the $\mathrm{CAB}$ wanted to examine multiple pathways of exposure, including the take-home pathway, a dietary pathway, an environmental pathway, and a lifestyle pathway. To do this, $\mathrm{CHC}$ and the CAB designed a cohort study to be conducted in the Valley [22], [34]. This longitudinal study collected samples of house dust, vehicle dust, urine, saliva, and blood from farmworker and non-farmworker families at three points during the agricultural season: the thinning, harvest, and non-spray seasons.

This cohort study took place in the Lower Yakima Valley of south-central Washington state between April 2005 and February 2006. The setting has been described elsewhere [21]. Briefly, the Valley covers both Yakima and Benton counties and includes not only the City of Yakima, but also many smaller communities whose economies are centered around agricultural production. Orchard crops include apples, pears, cherries, and peaches; hops and grapes are also grown in the region [1]. The Valley leads the state of Washington in apple production [35]. Most of the agricultural work in the Valley is done by farmworkers 
who are of Hispanic origin. Results from the United States Census indicated that in 2000 approximately 36\% of the population of Yakima County was of Hispanic origin; that figure rose to $45 \%$ in the 2010 Census [36], [37]. Agricultural work performed by Valley residents includes pruning, thinning, harvesting, and caring for the crop-bearing trees and vines.

Due to the project's organization as community-based participatory research, a community advisory board ( $\mathrm{CAB}$ ) was formed; details on $\mathrm{CAB}$ members have been described elsewhere [38]. The CAB provided input on the research questions to be pursued. Results from the previous study indicated that the occupational takehome pathway was a source of OP exposure for farmworkers' families [21]; thus the $\mathrm{CAB}$ was interested in further examining the introduction of agricultural pesticides into the home environments of children of agricultural workers compared to children of non-agricultural workers.

In this thesis we examine and report on the association between house dust concentrations of five of the Valley's most commonly used OPs (azinphos-methyl, chlorpyrifos, diazinon, phosmet, and malathion) and urinary dialkylphosphate (DAP) concentrations of farmworker adults, non-farmworker adults, and their children between the ages of 2 and 6 . We tested the hypothesis that adults and children living in homes with higher concentrations of OPs in house dust would have higher urinary metabolite concentrations of OPs, and that this relationship would differ significantly by occupation, agricultural season, and life stage. 


\section{METHODS}

\section{$\underline{\text { Recruitment of Subjects }}$}

All study materials and sample collection protocols were reviewed and approved by the Human Subjects Division of the University of Washington and the Institutional Review Board of the Fred Hutchison Cancer Research Center of Seattle, Washington (File \#5946). Informed consent was received from all participants. We recruited 100 farmworker adults and 100 non-farmworker adults, all of Hispanic origin and all with a referent child between the ages of 2 and 6 years at time of recruitment. Farmworker adults worked in pome fruit orchards in positions that included thinning, pruning, and harvesting, while non-farmworker adults worked in occupational settings such as schools, stores, daycare facilities, dairies, or factories. None of the farmworker adults worked as pesticide handlers during the time of this study. The same individuals were followed longitudinally across all three agricultural seasons. An expanded description of the demographic characteristics of the two cohorts can be found elsewhere [22]. Briefly, farmworkers were more likely to have been born in Mexico $(p<0.001)$, more likely to be married $(p<0.01)$, and less likely to live in a single-family home $(p<0.001)$ than non-farmworkers. Age distribution ( $p=0.83)$, gender ( $p=0.9)$, and number of children $(p=0.5)$ were not significantly different between the two groups.

\section{Sample Collection and Analysis}

$\mathrm{CHC}$ and the $\mathrm{CAB}$, working jointly, designed a study protocol to assess urinary metabolites of OPs in Hispanic adults and children of farmworker (FW) and nonfarmworker (NFW) families, as well as concentrations of OPs in house and vehicle 
dust. Adults and children participated in three data collection periods over the course of a year, which coincided with the three agricultural seasons typical of pome fruit cultivation. The first collection period (April through July 2005) coincided with the thinning season, when branches are pruned and buds are removed from the trees by hand to improve fruit development. The second collection period (August through October 2005) coincided with harvest season, when the fruit is picked. The third collection period (December 2005 through February 2006) coincided with the non-spray season, when the trees are dormant. OPs are applied to pome fruit trees primarily during the late non-spray season and throughout the thinning season, encompassing early spring to late summer [39], [40]. Because pruning and thinning are tasks that bring farmworkers into direct contact with treated foliage, the thinning season is thought to coincide with the highest exposure to OPs.

Urine

Three independent first-morning urine voids, each separated by two days (days 1, 3 and 5), were collected from each participant. Each sample was analyzed separately. Collections were repeated during each of the three agricultural seasons. Sampling protocols were based on standard procedures developed at the University of Washington [24]. Urine samples were collected in polypropylene containers with screw-cap lids. The containers were placed in individual plastic bags and then put on frozen ice packs in a cooler immediately after collection. Samples were collected by trained field staff and transferred to the field office where $10 \mathrm{~mL}$ urine was pipetted into 15-mL bottles; the samples were then frozen and stored in freezers at $10^{\circ} \mathrm{C}$ prior to being sent on dry ice to the laboratory at the Centers for Disease 
Control and Prevention (CDC) for analysis. Measurements were made via high performance liquid chromatography-linked tandem mass spectrometry (HPLCMS/MS) [41].

Urine was analyzed for the six DAP compounds that are produced by metabolism of most OP pesticides [42]. Dimethyl OPs are metabolized into one or more of three non-specific compounds: dimethylphosphate (DMP), dimethylthiophosphate (DMTP), and dimethyldithiophosphate (DMDTP). Diethyl OPs are also metabolized into one or more of three non-specific compounds: diethylphosphate (DEP), diethylthiophosphate (DETP), and diethyldithiophosphate (DEDTP). The OPs analyzed in this report are metabolized into five different DAPs (Figure 1).

\begin{tabular}{|ccc|}
\hline $\begin{array}{c}\text { Organophosphate } \\
\text { Pesticide }\end{array}$ & Class & $\begin{array}{c}\text { Dialkylphosphate Urinary } \\
\text { Metabolites }\end{array}$ \\
\hline Azinphos-methyl & Dimethyl OP & DMP, DMTP, DMDTP \\
\hline Malathion & Dimethyl OP & DMP, DMTP, DMDTP \\
\hline Phosmet & Dimethyl OP & DMP, DMTP, DMDTP \\
\hline Chlorpyrifos & Diethyl OP & DEP, DETP \\
\hline Diazinon & Diethyl OP & DEP, DETP \\
\hline
\end{tabular}

Figure 1. Urinary metabolites of organophosphate pesticides. None of the urinary metabolites is specific to an individual pesticide.

Metabolite levels were reported without measured creatinine correction [43]. The laboratory limits of detection (LOD) for the six urinary dialkylphosphate metabolites are shown in Figure 2. Chlorpyrifos and diazinon, both diethyl OPs, are metabolized into DEP and DETP but not DEDTP; therefore DEDTP results are not included in this analysis, but are reported in Tables 4A and 4B. 


\begin{tabular}{|ccc|}
\hline \multicolumn{3}{|c|}{$\begin{array}{c}\text { Laboratory Limits of DAP Detection } \\
\text { in Urine }\end{array}$} \\
\hline Metabolite & $\mathrm{ng} / \mathrm{mL}$ & $\mathrm{nmol} / \mathrm{mL}$ \\
\hline DMP & 0.6 & 0.005 \\
\hline DMTP & 0.2 & 0.001 \\
\hline DMDTP & 0.1 & 0.001 \\
\hdashline DEP & 0.2 & 0.001 \\
\hdashline DETP & 0.1 & 0.001 \\
\hdashline DEDTP & 0.1 & 0.001 \\
\hline
\end{tabular}

Figure 2. Limits of detection of dialkylphosphate metabolites of organophosphate pesticides in urine.

Dust

House dust samples were collected from the residences of the farmworkers and non-farmworkers with a Nilfisk vacuum cleaner. In each season, dust samples were collected on the same day that the household members provided their third urine samples. The residences were vacuumed once during each of the three collection periods described above. A cleaned vacuum and fresh polyliner bag, along with a clean vacuum hose and wand, were used for each household. Procedures for house and vehicle dust sampling were developed by the University of Washington and have been described elsewhere [24], [44]. Briefly, areas were vacuumed in a standardized manner. A square one-half meter by one-half meter template was used as a guide. Depending on flooring type, four to eight templates were vacuumed. In the homes, vacuuming was done over the area in which the parent reported that "the child played most frequently." In the household vehicles, the front and rear footwells (except in the case of trucks without rear footwells) were vacuumed thoroughly. After dust collection, the vacuum bag and polyliner were 
removed, placed in a plastic bag, and stored at $-10^{\circ} \mathrm{C}$ for transfer to the laboratory at the University of Washington for analysis. Dust samples were analyzed for residues of sixteen OPs according to the procedures described by Moate et al. [45]. The laboratory LODs for the five OPs detected in the highest concentrations are shown in Figure 3. These LODs were based on using one gram of dust in the analysis. In some cases less than one gram of dust was available for analysis, leading to some variability around the LODs.

\begin{tabular}{|ccc|}
\hline \multicolumn{3}{|c|}{ Laboratory Limits of OP Detection in Dust } \\
\hline OP & $\mathrm{ng} / \mathrm{g}$ & $\mathrm{nmol} / \mathrm{g}$ \\
\hline Azinphos-methyl & 10.0 & 0.033 \\
\hline Malathion & 0.4 & 0.003 \\
\hline Phosmet & 0.4 & 0.003 \\
\hline Chlorpyrifos & 4.0 & 0.026 \\
\hline Diazinon & 10.0 & 0.054 \\
\hline
\end{tabular}

Figure 3. Limits of detection of intact organophosphate pesticide residues in dust samples.

\section{Statistical Methods}

The data were log-transformed to analyze the concentration of OPs in house and vehicle dust and the concentration of OP metabolites in urine. In this paper, we report geometric mean (GM) concentrations of OPs in house dust and urinary OP metabolites with 95\% confidence intervals. Regression and correlation analyses were utilized to examine the relationship between OPs in dust, urinary OP metabolites, and parental occupation. Significance was determined based on the $p$ - 
value being less than 0.05 . With the exception of the Gibbs sampling (described below), all statistical analysis was performed using " $R$ " statistical software [46].

Concentrations of OPs in dust were characterized using a multivariate Normal distribution model with values below the LOD treated as censored values, similar to previous reports [47]. With this model we estimated the GM molar concentration of each OP population, geometric standard deviations, correlations between OPs, and standard errors of the parameters for FW and NFW households in each agricultural season. The model is described by:

$$
\begin{aligned}
& \log \left(X_{j k}\right) \sim \operatorname{MVN}_{5}\left(\theta_{k}, \Sigma\right) \\
& \text { for } j=1, \ldots, n_{j} \text {, and } k=1, . ., 5
\end{aligned}
$$

where $\mathrm{MVN}_{5}$ is a five-dimensional multivariate normal distribution of the OP pesticides azinphos-methyl, chlorpyrifon, diazinon, malathion, and phosmet. $X_{j k}$ is the vector of the $k=1, \ldots, 5$ measured OP concentrations of the $j$ th household. $\theta_{k}$ is the vector of the estimated mean concentrations in dust of the five OPs, and $\Sigma$ is the estimated variance-covariance matrix (5x5) among the five OPs. The number of households is $n_{j}$. Population standard deviations for each OP and correlations between OPs were estimated by the variance-covariance matrix $\Sigma$. Separate multivariate Normal distributions, $\mathrm{MVN}_{5}$, were estimated for each season, and for FW and NFW households. Samples with values below the limit of detection were treated as being censored at their level of detection. Because of the large number of dust samples below the LOD, distributions of the model parameters were estimated using a Bayesian Markov chain Monte Carlo method known as Gibbs sampling [47]. 
We discarded the first 5,000 simulations to initialize the Markov Chain and then retained 100,000 simulations to describe the joint distribution among the five OPs. Based upon plots of the simulations the Markov Chain appeared to mix rapidly and was stable [48]. Censored values are treated in each simulation as being from the lower tail of a multivariate Normal distribution with an upper cutoff at the limit of detection and the shape of the distribution determined by the parameter values for the simulation. This model was run using the WinBUGS 1.4 .3 software program available at www.mrc-bsu.cam.ac.uk/bugs [49]. These model simulations were used for the subsequent analyses of dust.

\section{Dust Samples}

The molar concentration (nmol/g) of each individual OP detected in the house and vehicle dust samples was calculated by dividing the concentration in nanograms per gram of the OP by its associated molecular weight in grams per mole. Total concentrations of dimethyl OPs and diethyl OPs were calculated by combining the concentrations of the individual OP samples from a given household or vehicle in a

given season. The concentrations of dimethyl OPs and diethyl OPs were then summed, resulting in total concentration of dialkyl OPs. In order to evaluate the relationship between OP residues in house dust and urinary OP metabolites, we included only those home dust samples for which at least one member of the household had given at least one urine sample. 


\section{Urine Samples}

Molar concentrations (nmol/mL) of dialkylphosphate metabolites were calculated by dividing the concentration of each urinary metabolite sample in nanograms per milliliter by its associated molecular weight in grams per mole. Within each season we included only those urine samples for which a house dust sample had been collected from the corresponding home. Because little research has been done on creatinine measurements in children under six years of age, our results were not adjusted for urinary creatinine concentration [50].

For each of the six dialkylphosphate metabolites analyzed, we calculated the GM of the molar concentrations $(\mathrm{nmol} / \mathrm{mL})$ in each participant's three urine samples within five days (days 1, 3, and 5) in a given agricultural season (thinning, harvest, or non-spray). We summed the GM concentrations of each participant's DMP, DMTP, and DMDTP results by season to determine the total concentration of dimethyl alkylphosphate metabolites (DMAP) by season, and similarly summed the GM concentrations of DEP and DETP by season to determine the total concentration of DEP+DETP by season. We then summed the total GM concentrations of DMAP, DEP, and DETP (DMAP+DEP+DETP) by season to obtain total GM concentrations by season of urinary dialkylphosphate metabolites synthesized from the five OPs analyzed in this report. We did not include DEDTP in these calculations because neither chlorpyrifos nor diazinon is metabolized into DEDTP. 


\section{RESULTS}

We analyzed house dust, vehicle dust, and urinary metabolites from 198 unique households. Of those 198 households, 119 households contributed urine and house dust samples for all three agricultural seasons, 62 households contributed samples for two seasons, and 17 households contributed samples for one season. The collected samples of house dust $(n=498)$ and vehicle dust $(n=270)$ were analyzed for sixteen OPs. The house dust samples were collected in thinning $(n=171)$, harvest $(n=170)$ and non-spray $(n=157)$ seasons, while the vehicle dust samples were collected in thinning $(n=150)$ and non-spray $(n=120)$ seasons. The collected samples of urine were analyzed for six DAPs. The urine samples were collected in thinning (171 adults plus 170 children), harvest (170 adults plus 170 children), and non-spray (157 adults plus 156 children). Details of the detection rates and concentrations of OP residues in the house and vehicle dust and OP metabolites in the urine are shown in Tables 2, 3, 4A, and 4B, indicating that there were occupational as well as seasonal trends in OPs found in house dust, vehicle dust, and urine.

\section{House Dust Samples}

In the house dust samples the five OPs detected most frequently (out of sixteen OPs tested) and in the highest concentrations were azinphos-methyl, malathion, phosmet, chlorpyrifos, and diazinon. Azinphos-methyl exhibited the highest rate of detection: it was found in $99 \%$ of the house dust samples collected from FW homes during thinning season, $98 \%$ of the samples from harvest season, and $95 \%$ of the samples from non-spray season, while in the NFW households azinphos-methyl was 
detected in $79 \%$ of the samples from thinning season, $95 \%$ of the samples from harvest season, and $65 \%$ of the samples from non-spray season (see Table 2).

Azinphos-methyl exhibited the highest GM concentration of OPs in house dust samples taken from both FW and NFW households. The GM concentration of azinphos-methyl in FW house dust in thinning season was $1.482 \mathrm{nmol} / \mathrm{g}$, while in harvest season it was $1.350 \mathrm{nmol} / \mathrm{g}$ and in non-spray season it was $0.372 \mathrm{nmol} / \mathrm{g}$.

FW house dust contained more azinphos-methyl than did NFW house dust in all three agricultural seasons: nine-fold more azinphos-methyl was detected in FW house dust samples than NFW samples during thinning season $(\mathrm{p}<0.001)$, four-fold more was detected in FW vs. NFW house dust during harvest season $(\mathrm{p}<0.001)$, and six-fold more was detected in FW vs. NFW house dust during non-spray season $(\mathrm{p}<0.001)$. FW household dust samples contained almost four-fold more azinphosmethyl in thinning season compared to non-spray season, reflecting the seasonal OP application patterns. In the Valley, azinphos-methyl is applied to pome fruits at periodic intervals during thinning season but not during harvest or non-spray seasons.

Of the five OPs analyzed in this report, chlorpyrifos exhibited the lowest rate of detection. In the FW households chlorpyrifos was detected in $60 \%$ of the dust samples collected during thinning season, $49 \%$ of the samples from harvest season, and $47 \%$ of the samples from non-spray season, while in the NFW households chlorpyrifos was detected in $29 \%$ of the samples from thinning season, $35 \%$ of the samples from harvest season, and $27 \%$ of the samples from non-spray season. 
In the FW households, diazinon was detected in the lowest GM concentration of the five OPs analyzed in thinning $(0.015 \mathrm{nmol} / \mathrm{g})$ and non-spray $(0.013 \mathrm{nmol} / \mathrm{g})$ seasons while chlorpyrifos was detected in the lowest GM concentration in harvest season $(0.023 \mathrm{nmol} / \mathrm{g})$. In the NFW households, chlorpyrifos was detected in the lowest GM concentration of the five OPs analyzed in all seasons $(0.005 \mathrm{nmol} / \mathrm{g}$ in thinning, $0.007 \mathrm{nmol} / \mathrm{g}$ in harvest, and $0.004 \mathrm{nmol} / \mathrm{g}$ in non-spray). In spite of the fact that chlorpyrifos was detected in comparatively low GM concentrations overall, FW house dust contained eight-fold more chlorpyrifos than NFW house dust in thinning season $(\mathrm{p}<0.001)$, three-fold more in harvest $(\mathrm{p}<0.001)$, and five-fold more in non-spray $(\mathrm{p}<0.001)$.

The GM concentration of chlorpyrifos fluctuated seasonally in FW but not NFW house dust samples. Samples from FW households had twofold more chlorpyrifos in thinning season compared to either harvest season or non-spray season, while NFW samples showed an insignificant variation across the three agricultural seasons that ranged from $0.004 \mathrm{nmol} / \mathrm{g}$ in non-spray to $0.007 \mathrm{nmol} / \mathrm{g}$ in harvest.

Figure 4a shows GM concentrations of the five most common OPs in house dust, in thinning and non-spray seasons. In thinning season, significant differences existed between FW and NFW households in the GM concentrations of azinphosmethyl $(p<0.001)$, chlorpyrifos $(p<0.001)$, diazinon $(p<0.05)$, phosmet $(p<0.001)$, and malathion $(p<0.001)$. In non-spray season, significant differences existed between FW and NFW households in the GM concentrations of azinphos-methyl $(\mathrm{p}<0.001)$, malathion $(\mathrm{p}<0.001)$, and chlorpyrifos $(\mathrm{p}<0.001)$. 


\section{Vehicle Dust Samples}

The five OPs analyzed in the vehicle dust samples were azinphos-methyl, malathion, phosmet, chlorpyrifos, and diazinon. The most frequently detected OPs in thinning season were azinphos-methyl and phosmet. We detected azinphosmethyl in $99 \%$ and phosmet in $98 \%$ of the dust samples taken from FW vehicles in thinning season, while vehicle dust from NFW vehicles in thinning season showed an azinphos-methyl detection rate of $79 \%$ and a phosmet detection rate of $80 \%$. In non-spray season the most frequently detected OPs were chlorpyrifos and azinphosmethyl. We detected chlorpyrifos in $65 \%$ and azinphos-methyl in $60 \%$ of the FW vehicle dust samples, while detecting chlorpyrifos in $41 \%$ and azinphos-methyl in $40 \%$ of the NFW vehicle dust see (Table 3 ).

Similar to the house dust findings, azinphos-methyl showed the highest GM concentration in vehicle dust samples. In thinning season, the GM concentration of azinphos-methyl in FW vehicle dust was $3.304 \mathrm{nmol} / \mathrm{g}$ while in non-spray season it was $0.064 \mathrm{nmol} / \mathrm{g}$. In the NFW vehicles, GM concentration of azinphos-methyl in thinning season was $0.206 \mathrm{nmol} / \mathrm{g}$ and in non-spray season it was $0.009 \mathrm{nmol} / \mathrm{g}$. FW vehicle dust contained more azinphos-methyl than did NFW vehicle dust in both agricultural seasons: sixteen-fold more azinphos-methyl was detected in FW samples than NFW samples during thinning season ( $\mathrm{p}<0.001)$, while seven-fold more was detected in FW samples than NFW samples during non-spray seasons $(\mathrm{p}<0.001)$. Vehicle dust from FW households contained over fifty-fold more azinphos-methyl in thinning season than in non-spray season $(\mathrm{p}<0.001)$ while NFW vehicle dust contained over twenty-fold more azinphos-methyl in thinning than 
non-spray season $(\mathrm{p}<0.001)$, reflecting the seasonal application patterns of azinphos-methyl in pome fruit orchards.

Figure $4 \mathrm{~b}$ shows GM concentrations of the five most common OPs in vehicle dust, in thinning and non-spray seasons. In thinning season, significant differences existed between FW and NFW households in the GM concentrations of azinphosmethyl $(p<0.001)$, chlorpyrifos $(p<0.001)$, diazinon $(p<0.001)$, phosmet $(p<0.001)$, and malathion $(p<0.001)$.
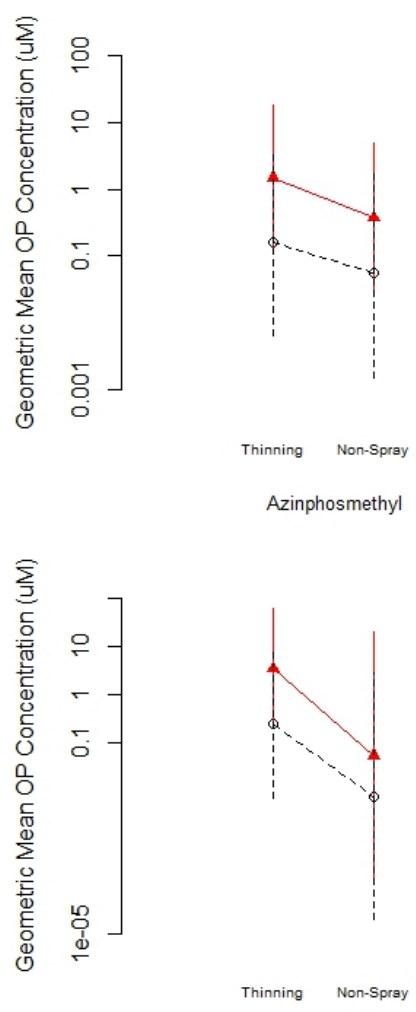

House Dust
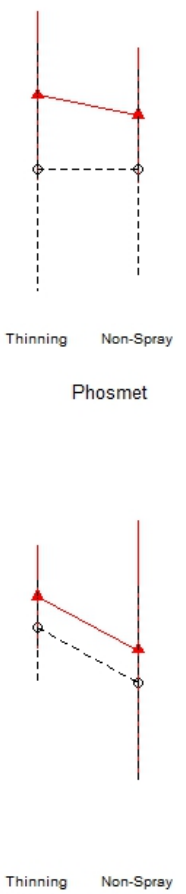

Malathion

Vehicle Dust
4 Farmworkers

- Non-Farmworkers
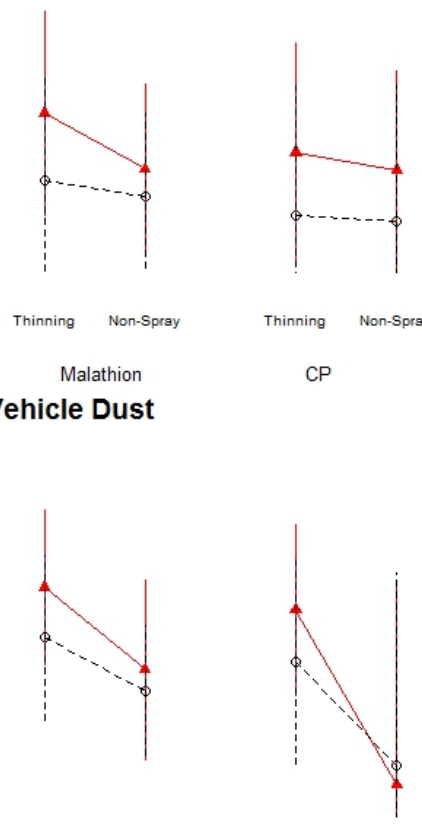

Farmworkers

- Non-Farmworkers
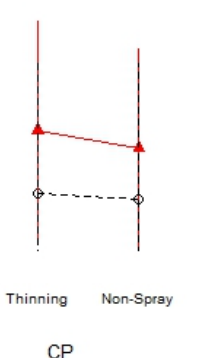

Thinning Non-Spray

Diazinon
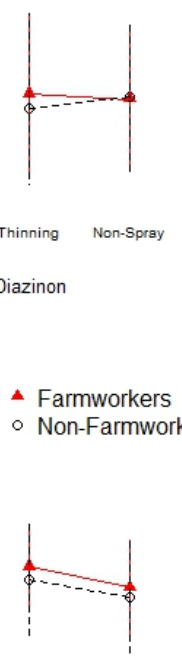

Thinning Non-Spray

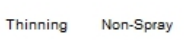

Thinning Non-Spray

Figure 4. Geometric mean concentration ( $\mathrm{nmol} / \mathrm{g})$ and $95 \%$ confidence interval of the five most abundant OPs detected in dust samples from farmworker and non-farmworker homes and vehicles, during thinning and non-spray seasons. (4a) Collected from residences, in the location where "the child played the most." (4b) Collected from primary household vehicle. 


\section{Urine Samples}

The urine samples were analyzed for the six non-specific DAPs characteristic of OP exposure (DMP, DMTP, DMDTP, DEP, DETP, and DEDTP; see Figure 1). Details of the number of participants, DAP detection rates, and DAP concentrations in child and adult urine samples are shown in Tables 4A and 4B.

\section{Child Urine}

In the child urine samples, DMAP was detected in significantly higher GM concentrations than DEP+DETP (see Table 4A for details). FW child urine showed eight-fold higher molar concentration of DMAP than DEP+DETP in thinning season, twenty-two-fold higher DMAP in harvest season, and six-fold higher DMAP in nonspray season. NFW child urine showed four-fold higher GM concentration of DMAP than DEP+DETP in thinning season, ten-fold higher DMAP in harvest season, and four-fold higher DMAP in non-spray season.

The GM concentration of DMAP in child urine peaked in harvest season. In FW child urine, DMAP was $0.205 \mathrm{nmol} / \mathrm{mL}$ in thinning season, $0.244 \mathrm{nmol} / \mathrm{mL}$ in harvest season, and $0.083 \mathrm{nmol} / \mathrm{mL}$ in non-spray season, while DMAP in NFW child urine was $0.102 \mathrm{nmol} / \mathrm{mL}$ in thinning season, $0.220 \mathrm{nmol} / \mathrm{mL}$ in harvest season, and $0.108 \mathrm{nmol} / \mathrm{mL}$ in non-spray season. FW children showed a two-fold higher concentration of DMAP than NFW children in thinning season $(\mathrm{p}<0.001)$.

Among the individual DAPs, DMTP was detected in the highest GM concentrations in urine from both groups of children within all three seasons. DMTP's GM concentration in FW child urine was $0.114 \mathrm{nmol} / \mathrm{mL}$ in thinning season, 
$0.161 \mathrm{nmol} / \mathrm{mL}$ in harvest season, and $0.041 \mathrm{nmol} / \mathrm{mL}$ in non-spray season, while DMTP in NFW child urine was $0.049 \mathrm{nmol} / \mathrm{mL}$ in thinning, $0.122 \mathrm{nmol} / \mathrm{mL}$ in harvest, and $0.047 \mathrm{nmol} / \mathrm{mL}$ in non-spray seasons. In thinning season, DMTP levels were two-fold higher in FW child urine than NFW child urine $(\mathrm{p}<0.001)$.

DMTP also showed the highest rate of detection in both FW and NFW child urine. In both thinning and harvest seasons, $100 \%$ of the children showed DMTP in at least one of their urine samples. In non-spray season, 100\% of FW children and 99\% of NFW children showed DMTP in at least one sample.

DETP was detected in the lowest GM concentrations in FW child urine in all three seasons $(0.013 \mathrm{nmol} / \mathrm{mL}$ in thinning season, $0.004 \mathrm{nmol} / \mathrm{mL}$ in harvest season, and $0.004 \mathrm{nmol} / \mathrm{mL}$ in non-spray season) and with the lowest rate of detection. Among FW children, 94\% showed DETP in at least one sample collected during thinning season, 57\% showed DETP in harvest season, and 64\% showed DETP in non-spray season. The pattern in the NFW children was slightly different: DETP was detected with the lowest frequency in thinning season (96\%) but DEP was detected with the lowest frequency in harvest (81\%) and non-spray (92\%). NFW children had two-fold more DEP than FW children in harvest season $(p<0.05)$ and three-fold more DEP in non-spray season $(\mathrm{p}<0.001)$.

DEDTP, which was excluded from this analysis, showed detection rates and GM concentrations that were less than either DEP or DETP. This observation held true for both groups of children, within all agricultural seasons. 


\section{$\underline{\text { Adult Urine }}$}

In the adult urine samples, DMAP was detected in significantly higher GM concentrations than DEP+DETP in both occupational groups within all three agricultural seasons (see Table 4B for details). FW adult urine showed a twentyfive-fold higher concentration of DMAP than DEP+DETP in thinning season, over forty-eight-fold higher DMAP in harvest season, and six-fold higher DMAP in non-

spray season. NFW adult urine showed four-fold higher molar concentration of DMAP vs. DEP+DETP in thinning season, twelve-fold higher DMAP in harvest season, and four-fold higher DMAP in non-spray season.

GM concentration of DMAP peaked in harvest season for both FW adults and NFW adults. DMAP in FW adult urine was $0.647 \mathrm{nmol} / \mathrm{mL}$ in thinning season, 0.666 $\mathrm{nmol} / \mathrm{mL}$ in harvest season, and $0.083 \mathrm{nmol} / \mathrm{mL}$ in non-spray season, while DMAP in NFW adult urine was $0.078 \mathrm{nmol} / \mathrm{mL}$ in thinning season, $0.240 \mathrm{nmol} / \mathrm{mL}$ in harvest season, and $0.087 \mathrm{nmol} / \mathrm{mL}$ in non-spray season. The GM concentration of DMAP in FW adults was eight-fold higher than NFW adults in thinning season $(p<0.001)$ and three-fold higher in FW adults in harvest season $(p<0.001)$.

Among the individual DAPs, DMTP was detected in the highest GM concentration in both FW and NFW adult urine samples collected within all three seasons. DMTP concentration in FW adult urine was $0.413 \mathrm{nmol} / \mathrm{mL}$ in thinning season, 0.468 $\mathrm{nmol} / \mathrm{mL}$ in harvest season, and $0.048 \mathrm{nmol} / \mathrm{mL}$ in non-spray season, while DMTP concentration in NFW adult urine was $0.036 \mathrm{nmol} / \mathrm{mL}$ in thinning, $0.129 \mathrm{nmol} / \mathrm{mL}$ in harvest, and $0.040 \mathrm{nmol} / \mathrm{mL}$ in non-spray seasons. Eleven-fold more DMTP was 
detected in FW adult urine in thinning season $(\mathrm{p}<0.001)$ and four-fold more was detected in FW adult urine in harvest season $(\mathrm{p}<0.001)$.

DMTP had the highest rate of detection in both FW and NFW adult urine. Within all three agricultural seasons, $100 \%$ of FW adults and 100\% of NFW adults had DMTP in at least one urine sample.

DETP showed the lowest rate of detection of the five OPs analyzed, in both FW and NFW adult urine, in all three seasons. The GM concentration of DETP in FW adult urine was $0.005 \mathrm{nmol} / \mathrm{mL}$ in thinning season, $0.002 \mathrm{nmol} / \mathrm{mL}$ in harvest season, and $0.004 \mathrm{nmol} / \mathrm{mL}$ in non-spray season, while DETP in NFW adult urine was $0.004 \mathrm{nmol} / \mathrm{mL}$ in thinning, $0.005 \mathrm{nmol} / \mathrm{mL}$ in harvest, and $0.004 \mathrm{nmol} / \mathrm{mL}$ in non-spray. FW adults had more DETP than NFW adults in thinning season $(\mathrm{p}<0.05)$ but less in harvest season $(\mathrm{p}<0.001)$.

DEDTP was not included in this analysis, but within all three agricultural seasons its GM concentration and rate of detection were less than either DEP or DETP for both FW and NFW adults.

Figure 5 compares DMAP and DEP+DETP in adults and children during thinning and non-spray seasons. FW adults showed an almost eight-fold reduction in urinary DMAP from thinning season to non-spray season and FW children showed a twofold reduction in DMAP during that same time frame. In contrast, urinary DMAP in NFW adults and children remained relatively constant from thinning to non-spray: NFW adults showed $0.078 \mathrm{nmol} / \mathrm{mL}$ DMAP in thinning and $0.087 \mathrm{nmol} / \mathrm{mL}$ DMAP in 
non-spray, while NFW children showed $0.102 \mathrm{nmol} / \mathrm{mL}$ DMAP in thinning and 0.108 DMAP nmol/mL in non-spray. Similar seasonal differences were seen with DEP+DETP: FW adult and FW child urine showed a reduction in DEP+DETP from thinning to non-spray while DEP+DETP GM concentration in NFW adult and NFW child urine remained relatively constant from thinning to non-spray (see Tables $4 \mathrm{~A}$ and $4 \mathrm{~B}$ for details).

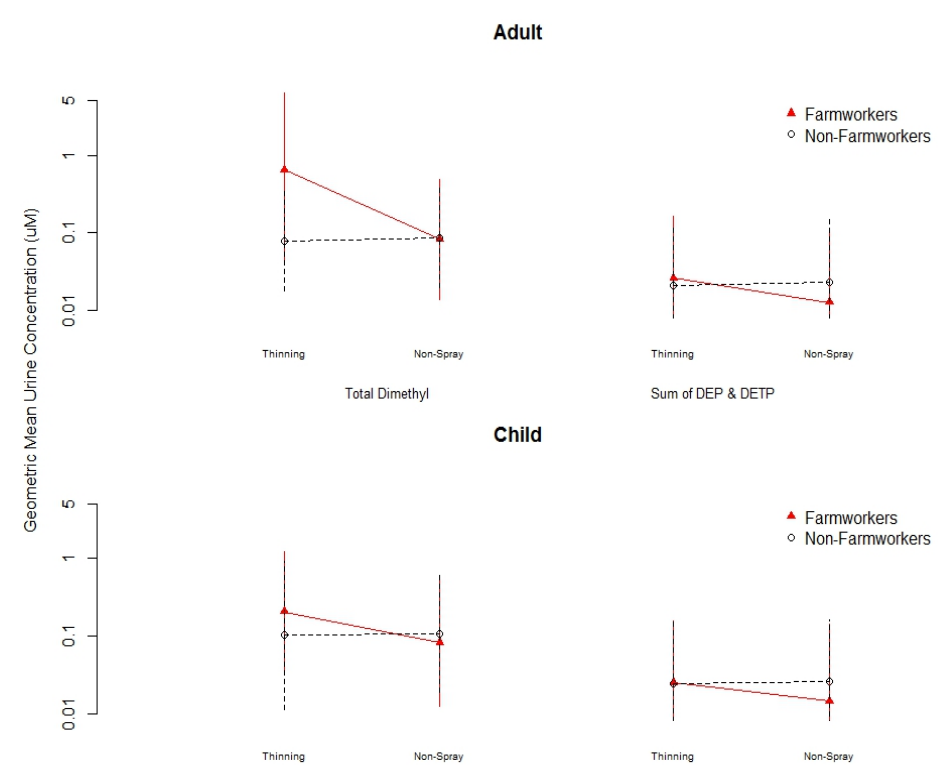

Figure 5. Geometric mean concentration (nmol/mL) and 95\% confidence interval of dimethylalkylphosphate (DMAP) and diethylphosphate plus diethylthiophosphate $(D E P+D E T P)$ urinary metabolites, collected from farmworker and non-farmworker adults and children during thinning and non-spray seasons. (5a) Adult DMAP. (5b) Adult DEP+DETP. (5c) Child DMAP. (5d) Child DEP+DETP.

Regression Analysis of Urine Dialkylphosphate Metabolites vs. House Dust OP

Residues

Regression analysis on log-transformed values was conducted to evaluate the relationship between the measured biologic levels of urinary OP metabolites in the study participants and the concentration of OP pesticide residues in household dust. 
Separate models were developed for the adults and the children, and for dimethyl and diethyl OPs. Initially we generated a simple regression model of urinary metabolites vs. OP residues in house dust. Results of that regression model indicated a significant positive relationship between all OP metabolites in urine vs. all OP residues in house dust for adults in thinning season $(p<0.001)$ and harvest season $(p<0.001)$ but not in non-spray season $(p=0.34)$. Similarly, a significant relationship existed for children in thinning season $(p<0.001)$ and harvest season $(p<0.05)$ but not in non-spray season $(p=0.84)$. We then added the independent categorical variable of parental occupation to the model and, utilizing a multiple regression model, examined whether there was an interaction between parental occupation and concentrations of OPs in house dust. We found a significant interaction for the adults in thinning season $(p<0.001)$ and harvest season $(p<0.001)$.

\section{Dimethyl OPs - Children}

Linear regression of log-transformed child DMAP vs. log-transformed dimethyl OP house dust residues found a significant positive relationship during thinning season $\left(p<0.001, \mathrm{r}^{2}=0.13\right)$ and harvest season $\left(p<0.05, \mathrm{r}^{2}=0.02\right)$ but not during nonspray season $(p=0.62)$. When parental occupation was considered as an independent categorical variable, the regression model indicated that there was an interaction between parental occupation and GM concentration of dimethyl OPs in house dust in harvest season $(p<0.05)$. The urinary DMAP concentration in the two groups of children (FW vs. NFW) differed significantly from one another in thinning $(p<0.001)$ and harvest $(p<0.05)$ seasons but not during non-spray season $(p<0.62)$. 
Figures $6 a, 6 b$, and $6 \mathrm{c}$ illustrate the dimethyl OP regression models for each agricultural season, with regression lines calculated separately for the two groups of children.

The equation which predicts child urinary DMAP in harvest season is

(Eq. 1) $\quad \log (y)=-1.49827+0.12318^{*}\left(\log \left(O P D M_{H}\right)\right)$

where $O P D M_{H}=$ concentration of dimethyl OP residues in house dust in harvest season.

Adding parental occupation and an interaction term between parental occupation and dimethyl OP residues in house dust gives the following predictive equation for child urinary DMAP in harvest season:

(Eq. 2) $\log (y)=-1.70440+0.26314^{*}\left(\log \left(O P D M_{H}\right)\right)+0.20714^{*}\left(P O_{H}\right)-$

$$
0.27356^{*}\left(P_{H}\right)^{*}\left(\log \left(O P D M_{H}\right)\right)
$$

where $O P D M_{H}=$ concentration of dimethyl OP residues in house dust in harvest season and $P O_{H}=$ parental occupation during harvest season $=1(\mathrm{FW})$ or $2(\mathrm{NFW})$.

\section{Dimethyl OPs - Adults}

The regression model of the log of adult DMAP vs. the log of dimethyl OP residues demonstrated the existence of a significant positive relationship between the concentration of dimethyl OP residues in house dust and the concentration of DMAP in adult urine during thinning season $\left(p<0.001, \mathrm{r}^{2}=0.40\right)$ and harvest season $\left(p<0.001, \mathrm{r}^{2}=0.04\right)$ but not during non-spray season $(p=0.16)$. When occupation was added to the regression model as an independent categorical variable, results indicated that an interaction existed between occupation and dimethyl OPs in house 
dust in thinning $(p<0.001)$ and harvest $(p<0.001)$ seasons. The DMAP concentration in the two occupational groups (FW adults vs. NFW adults) differed significantly from one another in thinning $(p<0.001)$ and harvest $(p<0.001)$ seasons but not during non-spray season ( $p=0.33$ ). Figures $6 \mathrm{~d}, 6 \mathrm{e}$, and $67 \mathrm{f}$ illustrate the dimethyl OP regression models for each agricultural season, with regression lines calculated separately for the FW and NFW adult populations.

The equation which predicts adult urinary DMAP in thinning season is (Eq. 3) $\log (y)=-1.42144+0.50290^{*}\left(\log \left(O P D M_{T}\right)\right)$ where $O P D M_{T}=$ concentration of dimethyl OP residues in house dust in thinning season.

Adding occupation and an interaction term between occupation and dimethyl OP residues in house dust gives the following predictive equation for adult urinary DMAP in thinning season:

(Eq. 4) $\log (y)=-0.93833+0.49282 *\left(\log \left(O P D M_{T}\right)\right)-1.46235^{*}\left(P O_{T}\right)-$ $0.37165 *\left(P O_{T}\right) *\left(\log \left(O P D M_{T}\right)\right)$ where $O P D M_{T}=$ concentration of dimethyl OP residues in house dust in thinning season and $P O_{T}=$ occupation during thinning season $=1(\mathrm{FW})$ or $2(\mathrm{NFW})$. 


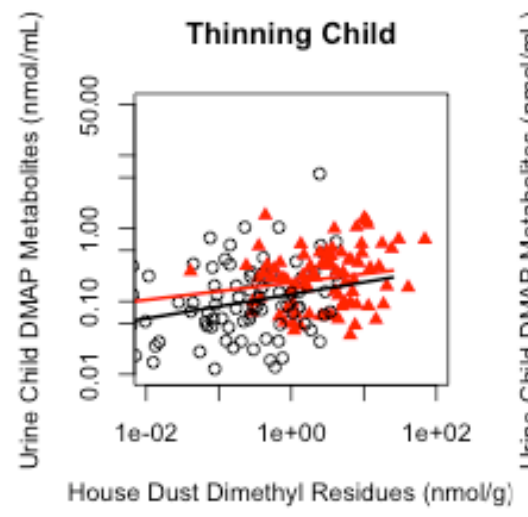

(6a)

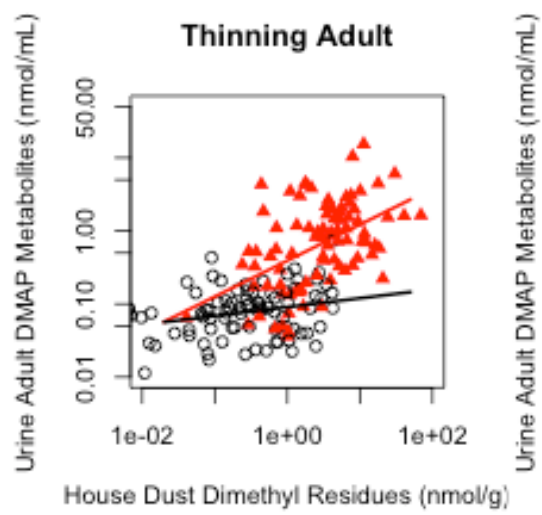

(6d)

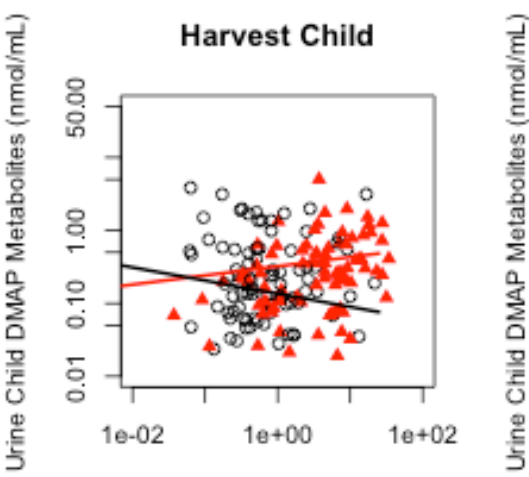

House Dust Dimethyl Residues (nmol/g)

(6b)

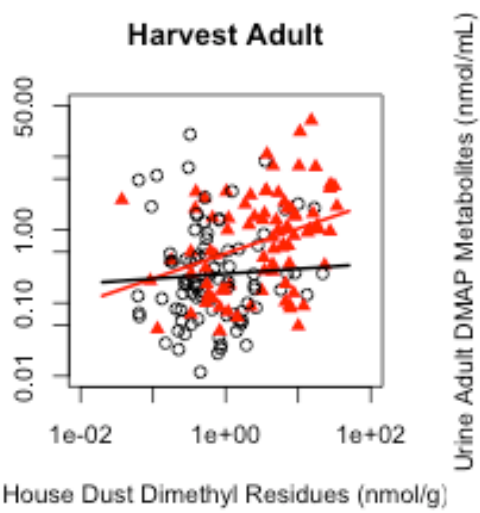

(6e)

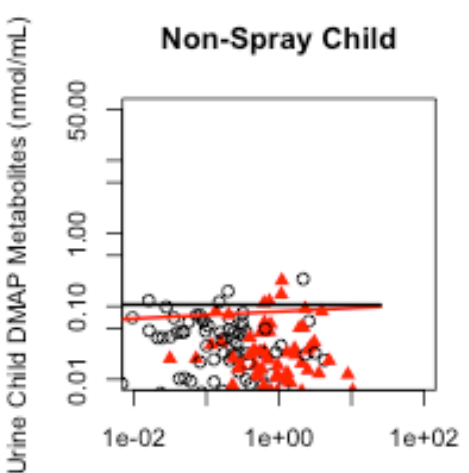

House Dust Dimethyl Residues (nmol/g)

(6c)

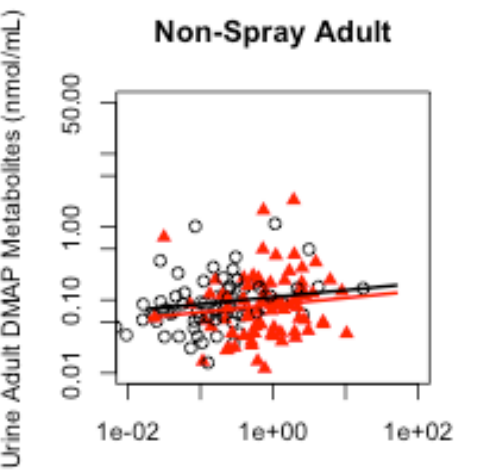

House Dust Dimethyl Residues (nmol/g)

(6f)

Figure 6: Regression of log of dimethylalkylphosphate (DMAP) urinary metabolites (nmol/mL) vs. log of dimethyl OP residues in house dust (nmol/g) by agricultural season, with regression lines calculated separately for the two occupational groups. All figures include samples with residue levels below LOD. (6a) Difference between urine of FW and NFW children in thinning season: $p<0.001$. (6b) Difference between urine of FW and NFW children in harvest season: $p<0.05$. (6c) Difference between urine of FW and NFW children in non-spray season: $p=0.62$. (6d) Difference between urine of FW and NFW adults in thinning season: $p<0.001$. (6e) Difference between urine of FW and NFW adults in harvest season: $p<0.001$. (6f) Difference between urine of FW and NFW adults in non-spray season: $p=0.33$. 


\section{Diethyl OPs - Children}

Although diethyl OPs were used less frequently than the dimethyl OPs during the agricultural seasons when urine and dust samples were collected [39], [51], we also performed regression analysis on the diethyl urinary metabolites and OP residues in house dust. Separate regression models were developed for adults and children.

Linear regression of log-transformed child DEP+DETP vs. log-transformed diethyl OP residues found a significant positive relationship between OP residues in house dust and DEP+DETP in child urine during thinning season $\left(p<0.05, \mathrm{r}^{2}=0.02\right)$ and harvest season $\left(p<0.05, \mathrm{r}^{2}=0.02\right)$ but not during non-spray season $(p=0.48)$. When parental occupation was considered as an independent categorical variable, the regression model indicated that there was an interaction between parental occupation and GM concentration of diethyl OPs in house dust in non-spray season $(p<0.05)$ but not in thinning or harvest seasons. The DEP+DETP concentration in the two occupational groups (FW children vs. NFW children) differed significantly from one another in harvest $(p<0.001)$ and non-spray $(p<0.05)$ seasons but not during harvest season ( $p=0.62)$. Figures $7 \mathrm{a}, 7 \mathrm{~b}$, and $7 \mathrm{c}$ illustrate the diethyl OP regression models for each agricultural season, with regression lines calculated separately for the FW and NFW child populations.

The equation which predicts child urinary DEP+DETP in harvest season is (Eq. 5) $\log (y)=-4.81280-0.19639 *\left(\log \left(O P D E_{H}\right)\right)$ where $O P D E_{H}=$ concentration of diethyl OP residues in house dust in harvest season. 
Adding parental occupation gives the following predictive equation for child urinary DEP+DETP in harvest season:

(Eq. 6) $\log (y)=-5.08134-0.12491^{*}\left(\log \left(O P D E_{H}\right)\right)+0.87286^{*}\left(P O_{H}\right)$

where $O P D E_{H}=$ concentration of diethyl OP residues in house dust in harvest season and $P O_{H}=$ parental occupation in harvest season $=1(\mathrm{FW})$ or $2(\mathrm{NFW})$.

\section{Diethyl OPs - Adults}

The regression model of the log of adult DEP+DETP vs. the log of diethyl OP residues demonstrated the existence of a significant positive relationship between the concentration of diethyl OP residues in house dust and the concentration of DEP+DETP in adult urine during thinning season $\left(p<0.001, \mathrm{r}^{2}=0.07\right)$ and non-spray season $\left(p<0.05, \mathrm{r}^{2}=0.03\right)$ but not during harvest season $(p=0.16)$. When occupation was added to the regression model as an independent categorical variable, results indicated that occupation was a significant factor affecting adults' urinary DEP+DETP in non-spray season $(p<0.001)$, and that significance of occupation approached our cut-off in harvest season $(p=0.053)$. The DEP+DETP concentration in the two occupational groups (FW adults vs. NFW adults) differed significantly from one another in harvest season $(p<0.05)$ and non-spray $(p<0.001)$ season but not during thinning season ( $p=0.15$ ). Figures $7 d, 7 \mathrm{e}$, and $7 \mathrm{f}$ illustrate the diethyl OP regression models for each agricultural season, with occupation as a separate categorical variable and regression lines calculated separately for the FW and NFW adult populations. 
The equation which predicts adult urinary DEP+DETP in non-spray season is (Eq. 7) $\log (y)=-4.62711-0.14406^{*}\left(\log \left(O P D E_{N}\right)\right)$ where $O P D E_{N}=$ concentration of diethyl OP residues in house dust in non-spray season.

Adding occupation gives the following predictive equation for adult urinary DEP+DETP in non-spray season:

(Eq. 8) $\log (y)=-4.84490-0.10982^{*}\left(\log \left(O P D E_{n}\right)\right)+0.65536^{*}\left(P O_{N}\right)$ where $O P D E_{N}=$ concentration of diethyl OP residues in house dust in non-spray season and $P O_{N}=$ occupation in non-spray season $=1(\mathrm{FW})$ or $2(\mathrm{NFW})$. 


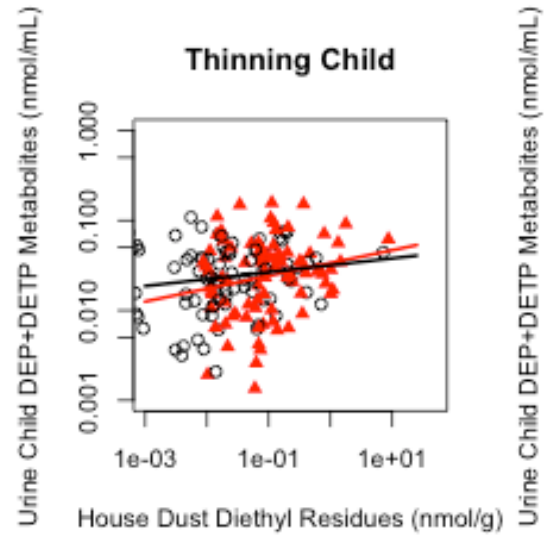

(7a)

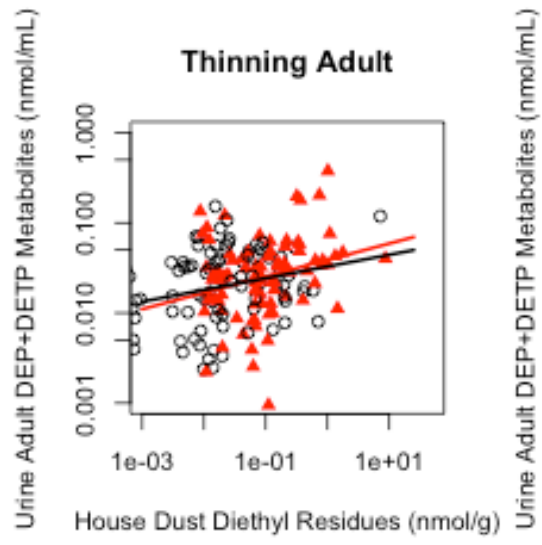

(7d)

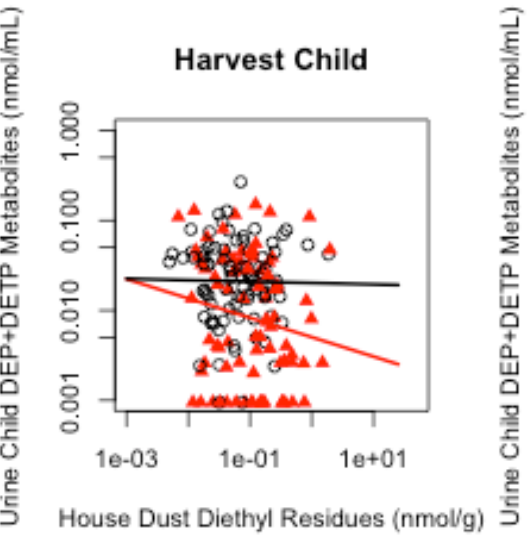

(7b)

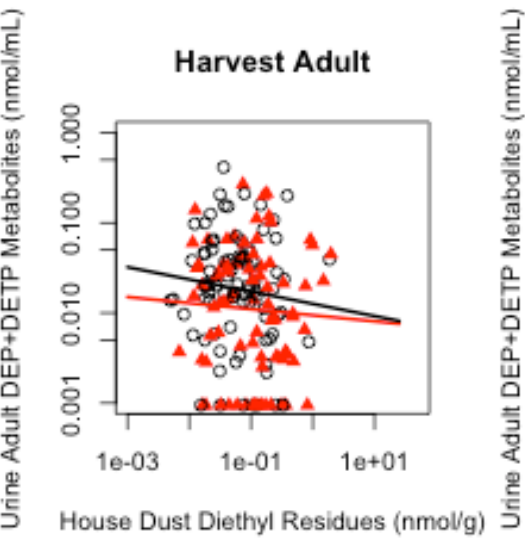

$(7 e)$
Non-Spray Child

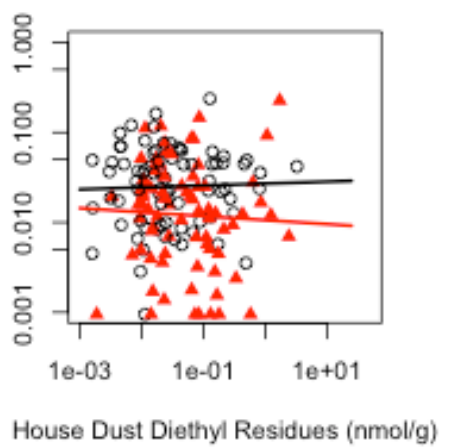

(7c)

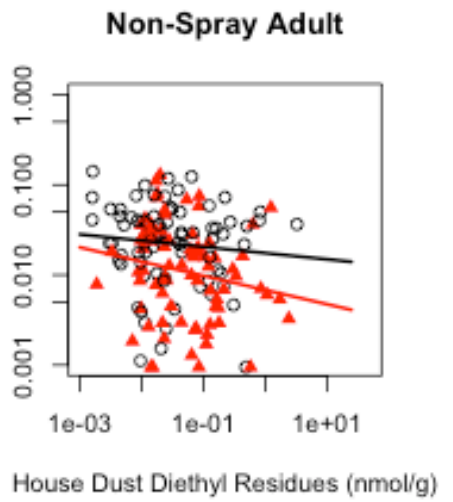

(7f)

Figure 7: Regression of log of diethylphosphate plus diethylthiophosphate (DEP+DETP) urinary metabolites (nmol/mL) vs. log of diethyl OP residues in house dust (nmol/g) by agricultural season, with regression lines calculated separately for the two occupational groups. All figures include samples with residue levels below LOD. (7a) Difference between urine of FW and NFW children in thinning season: $p<.05:$ (7b) Difference between urine of FW and NFW children in non-spray season: $p<.001$. (7c) Difference between urine of FW and NFW children in non-spray season: $p<.05$. (7d) Difference between urine of FW and NFW adults in thinning season: $p<0.05$. (7e) Difference between urine of FW and NFW adults in harvest season: $p=0.06$. (7f) Difference between urine of FW and NFW adults in non-spray season: $p<0.05$. 


\section{Relationship Between Child and Adult Urinary OP Metabolites}

Using linear regression, we analyzed the GM concentrations of child vs. adult urinary DAPs. A significant positive relationship existed between child DMAP vs. adult DMAP in thinning season $(p<0.001)$, harvest season $(p<0.001)$, and non-spray season $(p<0.001)$. When parental occupation was added to the regression model as an independent categorical variable, results became more significant in harvest season $(p<0.001)$ and non-spray season $(p<0.001)$. Addition of an interaction term between parental occupation and adult DMAP did not further strengthen the results of the regression model in any season.

In the analysis of DEP+DETP we found that a significant positive relationship existed between child DEP+DETP vs. adult DEP+DETP in thinning season $(p<0.001)$, harvest season $(p<0.001)$, and non-spray season $(p<0.001)$. When parental occupation was added to the regression model as an independent categorical variable, the results were significant in harvest season $(p<0.001)$ and non-spray season $(\mathrm{p}<0.001)$. Addition of an interaction term between parental occupation and adult DEP+DETP did not strengthen the results of the regression model in any season.

Relationship Between Child-to-Adult Ratio of Urinary OP Metabolites and House Dust OP Residues

The study participants were matched pairs of adult and child, with each child residing in the same home as the paired adult and all participants being of Hispanic origin. We investigated whether a relationship existed between the ratio of the 
child's urinary OP metabolites to the parent adult's urinary OP metabolites vs. house dust OP residues. For dimethyl OPs, we found that the relationship between childto-parent DMAP ratio and dimethyl OP house dust residues was significant in thinning season $(p<0.001)$ and harvest season $(p<0.05)$. When parental occupation was added to the regression model as an independent categorical variable, results indicated that parental occupation was a significant factor in this relationship in thinning season $(\mathrm{p}<0.001)$ and harvest season $(p<0.001)$. We did not find a significant relationship in any season between the child-to-parent DEP+DETP ratio vs. diethyl OP house dust residues.

Proportional DMAP components in FW vs. NFW adults and FW vs. NFW children

DMP urinary concentration in FW children was less than in NFW children ( $p<0.001$ in thinning, $p<0.001$ in harvest, and $p<0.05$ in non-spray), and DMTP urinary concentration was greater in FW children than NFW children $(p<0.05$ in thinning, $p<0.001$ in harvest, and $p<0.05$ in non-spray) (Table 5A). DMDTP urinary concentration in FW children was greater than in NFW children in thinning season $(p<0.05)$ and less in FW children than NFW children in harvest season $(\mathrm{p}<0.001)$. This trend of a lower concentration of urinary DMP and higher concentration of urinary DMTP in FW children's urine samples was also exhibited by the adults: DMP urinary concentration in FW adults was less than in NFW adults $(p<0.001$ in thinning, $p<0.001$ in harvest, and $p<0.001$ in non-spray), and DMTP urinary concentration was higher in FW adults than in NFW adults $(p<0.001$ in thinning, $p<0.001$ in harvest, and $p<0.001$ in non-spray) (Table 5B). DMDTP urinary concentration was lower in FW adults than NFW adults in harvest season $(p<0.001)$. 


\section{DISCUSSION}

In this study, we evaluate the association between intact organophosphate pesticide residues in the household dust of families of Hispanic farmworkers and non-farmworkers living in agricultural communities in the lower Yakima Valley, and urinary metabolites of those pesticides. The detection of DAPs in urine indicates recent OP exposures, since OPs are metabolized within 24-48 hours [52]-[55]. The FW adults would have been exposed during the course of their ordinary occupational duties, but neither the NFW adults nor any of the children would have experienced occupational exposure so the presence of urinary DAPs indicates exposure from other sources.

Our data showed that a positive correlation existed between the concentrations of adult urinary DMAP+DEP+DETP vs. house dust OP residues in thinning season, when OPs are being applied regularly, and also during harvest season, when OPs are applied sporadically. During non-spray season, the data showed no association between adult DMAP+DEP+DETP and house dust OP residues. Children reflected the same pattern: the data showed a positive correlation between the concentration of child DMAP+DEP+DETP and house dust OP residues during thinning season and harvest season but not during non-spray season.

Analyzing dimethyl OPs and metabolites separately from diethyl OPs gave further insight into the relationship between contaminated house dust and pesticide metabolites in urine. A positive correlation was seen between urinary DMAP and dimethyl OP residues in house dust, in thinning and harvest seasons but not in non- 
spray season, for both the adults and for the children. When occupation (FW vs. NFW) was included as a separate variable in the regression model, an interaction between occupation and dimethyl OPs in house dust was observed in thinning season and harvest season, for the adults but not the children. Thus our data showed that an association existed between pesticide-contaminated house dust and the amount of pesticide metabolites in the children's urine, in thinning season when OPs are applied to pome orchards regularly, and also during harvest season when fewer OPs are used. The same association was seen in adults, and in addition, an association was also present between adult occupation and urinary pesticide metabolites.

A somewhat different pattern was seen in the relationship between urinary DEP+DETP and diethyl OP house dust residues. A positive correlation between adult DEP+DETP and diethyl OPs was seen in thinning and non-spray seasons but not in harvest season, while a positive correlation was seen in the children in thinning and harvest seasons but not non-spray season. When parental occupation was introduced into the model as an independent categorical variable, the results showed that parental occupational status as a farmworker influenced the concentration of urinary DEP+DETP significantly in harvest and non-spray seasons, for both adults and children. Thus parental occupation affected the children's concentration of urinary DEP+DETP in harvest and non-spray seasons, but it had no effect on DEP+DETP in thinning season, nor did it affect the concentration of diethyl OPs in house dust in any season. 
We found a significant correlation between the ratio of child-to-parent urinary DMAP and concentration of dimethyl OPs in house dust, in thinning harvest seasons. The addition of parental occupation as an independent variable strengthened the correlation, demonstrating that a relationship existed between the parent's occupation and the ratio of DMAP between the adult and the child. Addition of an interaction term between house dust and parental occupation gave significant results in thinning season, indicating that parental occupation influenced the concentration of dimethyl OPs in house dust in thinning season.

These results support our hypothesis that, in certain agricultural seasons, there exists a pesticide take-home pathway, in which adult farmworkers exposed occupationally to OPs carry the pesticide residues into the vehicles and then into the homes, increasing the likelihood that children living in those homes will be exposed to OPs. While the children are not exposed occupationally to organophosphate pesticides, our analysis indicates that during certain times of the year a parent's occupational status as a pome fruit worker affects both their children's levels of urinary OP metabolites and the concentrations of OPs in their homes.

Our paper is not the first to investigate OP residues in house dust and OP metabolites in the urine of adults and children living in those homes [56], but to our knowledge it is the first to report on an association between pesticides in house dust and their biological metabolites in urine. Our study is unique in that it collected urine and dust data across three agricultural seasons, from a cohort of farmworker and non-farmworker adults and their children living in agricultural communities in 
the Lower Yakima Valley of Washington state. All of the FW adults were employed with the same agricultural crop (pome fruits) during the sample collection periods, thereby ensuring that their occupational OP exposure profiles were similar.

Several previous studies have measured pesticide residues in the vehicles that farmworkers use for transportation to their workplaces. A study of agricultural workers in Washington state found that pesticide handlers had higher levels of azinphos methyl in vehicle dust than did non-handlers; vehicle and house dust concentrations of azinphos methyl were highly associated [23]. Data from a cohort of farmworkers in the Valley showed the presence of OPs on all types of vehicle flooring; vehicles with no floor mat or a plush floor mat had a higher mass of dust than vehicles with a hard mat flooring [44]. We found that the patterns of OP residue detection in the vehicles of FW and NFW families reflected the patterns of OP detection in house dust, with the residue of all five OPs tested being significantly higher in FW homes and vehicles than non-FW homes and vehicles during thinning season.

Azinphos-methyl, a dimethyl OP, is considered to be one of the most effective pesticides against the codling moth and was applied in significant quantities in the Valley during 2005 and 2006, primarily during thinning season. Azinphosphosmethyl, a dimethyl OP, is a potential source of the urinary DMAPs found in this study's participants. In this study, azinphos-methyl was the most commonly detected OP in both house dust and vehicle dust, while DMTP was the most commonly detected urinary metabolite in both adults and children. Chlorpyrifos, a 
diethyl OP, is also effective against the codling moth and it was applied in significant quantities in the Valley during 2005 and 2006. Its application period of FebruaryMarch overlapped but did not coincide exactly with the urine sampling intervals, which may explain the low levels of chlorpyrifos detected in this study. Chlorpyrifos and diazinon were the least commonly detected OPs in house and vehicle dust, and DEP+DETP were the least commonly detected urinary metabolites in adults and children. The patterns of OP presence in house dust, vehicle dust, and urinary metabolites reflect the patterns of orchard application, giving support to the hypothesis that adults who work in agricultural settings carry pesticides into their vehicles and then into their homes and thereby expose family members to workplace contaminants.

Of the six urinary OP metabolites analyzed, we detected dimethyl OP metabolites (DMTP and DMP) with the highest frequency and in the highest concentrations, which is consistent with the findings of several other studies. Thompson et al. found DMTP in $88 \%$ of a cohort of 211 children and in $92 \%$ of a cohort of 213 adults, all from the Valley; the researchers measured OPs in house dust and found azinphosmethyl in the highest concentrations [21]. Lambert et al. reported finding DMTP in $79 \%$ of a group of 176 children living in three agricultural communities in Oregon but did not attempt to measure pesticides in the children's homes [57]. QuirosAlcala et al. found DMTP in 95\% of the urine samples taken from 20 children living in an agricultural community in California and in $90 \%$ of the samples of 20 children living in an urban community in the state; the researchers measured DAPS in house dust and found DEP most frequently [56]. In a random sampling from the National 
Health and Nutrition Examination Survey (NHANES) database, DMTP was detected in $64 \%$ of the urine samples of 1,139 children ages 8 to 15 years of age [30].

Grandjean et al. found DMP in the highest concentrations in a group of 72 Ecuadorean children [58], and Sánchez Lizardi et al. found DMP in 100\% of the urine samples of 48 children living in southern Arizona [59]. It is possible that the dominance of dimethyl OP metabolites in these children's urine is an indication that children are exposed more frequently to dimethyl OPs, in spite of the fact that diethyl OPs are used commonly on agricultural crops. This is an area in which further research would elucidate a link between pesticide usage and population exposure.

Urine and dust collection periods coincided with the three agricultural seasons typical of pome fruit cultivation: non-spray (from the end of December to midMarch), thinning (April through mid-August), and harvest (September through November). OP spraying in pome fruit orchards begins late in the non-spray season with chlorpyrifos, which growers are only licensed to apply when the trees are in the pre-bloom stage. As buds and leaves develop, azinphos-methyl, diazinon, malathion, and phosmet are applied during this period of late spring and summer when farmworkers are thinning and pruning the trees actively [39], [40]. After each OP application a re-entry interval (REI) is imposed, during which time farmworkers may not work in the orchards. The duration of the REI varies according to the specific $\mathrm{OP}$, and lasts from 12 hours (malathion) to 4 days (chlorpyrifos and diazinon) and 5 days (phosmet) to 15 days (azinphos-methyl) [51]. OP application ceases at a fixed time interval before fruit harvesting commences, in order to 
minimize the OP residues on harvested fruit; this pre-harvest interval is 7 days for phosmet and 21 days for azinphos-methyl and diazinon [51]. Use of OPs on pome fruits does not resume until late winter of the following year, when chlorpyrifos is applied in order to target over-wintering insects.

We compared our findings to data collected by the Center for Disease Control and Prevention (CDC), which provides an ongoing assessment of the exposure of the U.S. population to environmental chemicals by the use of biomonitoring [60]. In each survey period, chemicals or their metabolites are measured in blood, serum, and urine samples from random subsamples of about 2.500 participants from NHANES conducted by the CDC's National Center for Health Statistics. NHANES is a series of surveys designed to collect data related to the health and nutritional status of the U.S. population. For chemicals measured in urine, NHANES presents its data in two ways, with and without adjustment for creatinine concentration. Our results were compared to NHANES results that had not been adjusted for creatinine concentration. NHANES' published data from 2005-06 indicates that, in a sample of approximately 350 children ages 6-11 years old (the youngest age group surveyed), the only urinary dialkylphosphate metabolite detected in concentrations high enough to provide a valid result was DMTP (see Table 6A). GM molar concentration of DMTP in the NHANES children ages 6-11 was $0.019 \mathrm{nmol} / \mathrm{mL}$, while for FW children the GM concentration of DMTP ranged from $0.041 \mathrm{nmol} / \mathrm{mL}$ in non-spray season (two-fold higher than NHANES) to $0.161 \mathrm{nmol} / \mathrm{mL}$ in harvest season (eightfold higher). For NFW children the GM concentration of DMTP ranged from 0.049 
$\mathrm{nmol} / \mathrm{mL}$ in thinning and $0.047 \mathrm{nmol} / \mathrm{mL}$ in non-spray (two-fold higher than NHANES) to $0.119 \mathrm{nmol} / \mathrm{mL}$ in harvest season (six-fold higher).

The youngest children in the NHANES data are 6-11 years old, which is older than most of the children in this study (who were 2-6 years old at the time of recruitment). Nevertheless, the NHANES data serves as a point of comparison for urinary DAPs, which can indicate potential OP exposure. Only a single dialkylphosphate metabolite, DMTP, was detected in the urine of the NHANES children in quantities sufficient to provide a valid result. In contrast, the dimethyl metabolites DMP, DMTP and DMDTP were detected with high frequency in the urine of the children in this study (most notably during thinning season), and the diethyl metabolites DEP and DETP were detected in at least half of the adult and child subjects of this study. Both FW and NFW children living in the Valley show higher urinary DMTP in every season than the NHANES children, which may be an indication that all children living in an agricultural community have higher exposure to agricultural pesticides.

For adults, NHANES' published data from 2005-06 indicates that, in a sample of approximately 1,092 adults ages 20-59 years old, the only dialkylphosphate metabolite detected in urine in concentrations high enough to provide a valid result was DMTP (see Table 6B) [60]. GM molar concentration of DMTP in the NHANES adults ages 20-59 was $0.012 \mathrm{nmol} / \mathrm{mL}$, while for $\mathrm{FW}$ adults the GM concentration of DMTP ranged from $0.048 \mathrm{nmol} / \mathrm{mL}$ in non-spray season (a four-fold increase over NHANES) to $0.472 \mathrm{nmol} / \mathrm{mL}$ in harvest season (a thirty-nine-fold increase). For 
NFW adults the GM concentration of DMTP ranged from $0.037 \mathrm{nmol} / \mathrm{mL}$ in thinning and non-spray seasons (a three-fold increase over NHANES) to $0.131 \mathrm{nmol} / \mathrm{mL}$ in harvest season (a ten-fold increase).

Young children are exposed to OPs primarily in their homes, daycare settings, and schools, since they spend up to 21 hours per day indoors [61]. Intact OPs can remain stable indoors for periods of time lasting from months to years [62]. Thus children can be exposed to pesticides through the take-home pathway, as the OP residues carried on parental clothing, shoes, skin, and hair to vehicles and homes are transferred to house dust. Children are of particular concern when investigating exposures to pollutants carried in house dust due to their frequent hand and mouthing behaviors [63]-[66]. Because of these contact and mouthing activities, children may have high exposures to dust-borne pollutants transferred to hands, objects, and even food, especially if the objects or food have been on the floor [67]. Most OPs are not ionized and are lipophilic, so inhaled or swallowed material will be taken up relatively easily [52]. Small children could absorb a substantial amount of the pesticides carried on their hands and into their mouths via this unique exposure pathway.

Agricultural pesticides carried in house dust can be a source of exposure to the inhabitants. Dust samples taken from 28 farmworker and urban homes in California were analyzed for 25 pesticides [68]. The majority of homes (93\%) had at least three different pesticides detected in house dust. Diazinon and chlorpyrifos were detected in $79 \%$ and 55\%, respectively, of the samples from farmworker homes and 
in $55 \%$ and $36 \%$ of the samples from urban homes. The authors estimated that nondietary pesticide intake for resident children did not exceed the then-current U.S. Environmental Protection Agency's recommended chronic reference dose. In a separate study, dust samples from 40 homes in farmworker and urban communities in California and urine samples from resident children ages 3-6 were all analyzed for the six DAPs characteristic of OP exposures [56]. The dust samples were also analyzed for eight intact OPs. DEP was the most commonly detected DAP in house dust and DMTP the least commonly detected. Diazinon and chloryrifos were the most commonly detected intact OPs in house dust. The most frequently detected urinary DAP in both groups of children was DMTP, and the least frequently detected was DEDTP. DEP dust concentrations were not correlated with chlorpyrifos or diazinon dust concentrations, even though DEP is an environmental degradation product of both chlorpyrifos and diazinon. House dust DEP was not correlated with urinary DEP, and neither diazinon dust nor chlorpyrifos dust was associated with either urinary DEP or urinary DEP+DETP [56].

There is general acknowledgement that DAPs are available from food. OPs on food commodities degrade to DAPs at levels which may approach that of the parent OP [69]. At this time there is little understanding of whether ingested DAPs are further metabolized. In Sprague-Dawley rats, approximately 30\% of an administered dose of DMP was recovered unchanged in urine, while virtually all of a dose of DEP but only $50 \%$ of a dose of DETP were recovered in urine, suggesting that at least some DAPs are further metabolized after oral ingestion [53], [54]. A portion of the DAPs detected in the urine of this study's subjects may well have 
originated from ingestion of DAPs found on food or in the environment rather than from metabolism of the parent OP compounds. However, in this report we did not attempt to predict OP exposure based on urinary DAPs; rather we examined whether there was an association between intact OPs in house dust and the urinary DAPs detected in FW and NFW families living in an agricultural area.

Children living in communities with agriculture-based economies appear to have generally higher exposure to OPs than their peers living in non-agricultural communities. Our data indicate that both FW and NFW children have higher OP urinary metabolite levels compared to the 6-11 year old children in the NHANES database (Table 6A). Urine samples from 176 Oregon children ages 2-6 showed that the children living in three selected agricultural communities had significantly more DMTP in their urine than did the reference group living in an urban, nonagricultural setting [57]. Seventy-eight children ages 4-6 from agricultural and nonagricultural communities in Oregon and North Carolina completed a series of neurobehavioral tests. The children living in agricultural communities showed worse performance on measures of response speed and latency as compared to their peers living in non-agricultural communities [70].

Only a few studies have been conducted examining the relationship between postnatal OP exposure and the neurodevelopment of school-age children, and the results are inconsistent. Cross-sectional data from the U.S. National Health and Nutrition Examination Survey were analyzed, and 119 of 1,139 children ages 8-15 met the diagnostic criteria for attention deficit hyperactivity disorder (ADHD). 
Children with higher urinary DMAP concentrations were more likely be diagnosed as having ADHD, while diethyl alkylphosphate (DEAP) levels were not significantly associated with the odds of ADHD [30]. Researchers assessed the development of 79 children from Ecuador: the urinary DAP levels of the 7-year-old children were associated with an increase in simple reaction time [58]. Analysis of data on 1,081 children ages 6-11 years from the Canadian Health Measures Survey found urinary DAPs in $91 \%$ of the children, but urinary DAPs were not associated significantly with a high level of parent-reported behavioral problems [71]. In a group of 48 children from the Children Pesticide Survey of southern Arizona, 100\% of the children had detectable levels of the OP metabolite DMP. Higher urinary DAPs were correlated significantly with poorer performance on some subsets of the Wisconsin Card Sorting Test, although results were dependent upon the inclusion of two samples with significantly higher DAPs [59]. In a cohort of 323 five-year-old Mexican-American children in California, researchers found that, although there was no association between total DAPs and measures of attention, there was a doubling of the odds of ADHD for every 10-fold increase in urinary DEAP [72]. The effect of long-term, low-level exposures to OP pesticides, especially among children who live in agricultural areas where pesticides are applied continuously, remains open to investigation.

Several longitudinal studies have examined the relationship between prenatal exposure to OPs and neurological development during early childhood, and the results indicate not only that exposure to OPs is widespread among women of childbearing age, but that there may be a link between in utero OP exposure and 
early cognitive development. Urine samples were obtained from a cohort of predominantly Latina pregnant farmworkers living in Salinas, California; the urine samples, which were collected at two time points during the pregnancy, were measured for the six DAPs characteristic of OP exposure [73]. Urine was collected at two time points during pregnancy. Age-appropriate neurological tests were administered to the offspring at 3 days, 3.5 years, 5 years, and 7 years [72]-[74]. A significant association was found between the mother's levels of urinary DAP during pregnancy and the number of abnormal reflexes shown by their 3-day-old infants [73]. Maternal prenatal DAP was non-significantly associated with maternal reports of attention problems and attention-deficit/hyperactivity disorder (ADHD) at age 3.5 years but was significantly related at age 5 years [72]. Maternal prenatal DAP was also significantly associated with poorer intellectual development at 7 years of age [74]. DAP levels in the urine of the 7-year-olds were not consistently associated with poorer cognitive scores. A second longitudinal study followed a cohort of African-American and Dominican mothers and children living in New York City [75]. Cord blood and maternal blood samples taken post-partum were analyzed for plasma levels of the OP chlorpyrifos. Age-appropriate neurological tests were administered to the offspring at 3 and 7 years old [76], [77]. At age 3, children exposed to higher levels of chlorpyrifos were significantly more likely to experience psychomotor and mental development delays, attention problems, ADHD, and pervasive developmental disorders (PDD) [76]. At age 7, the children exhibited a $1.4 \%$ decline in intelligence quotient and a $2.8 \%$ decline in working memory for each standard deviation increase in prenatal chlorpyrifos exposure [77]. A third 
longitudinal study followed a cohort of multi-ethnic women and their children in New York City [78]. Maternal urine was collected once, during the third trimester of pregnancy, and analyzed for DAP and malathion dicarboxylic acid. Age-appropriate neurological tests were administered to the offspring at 2 days postpartum, 12 months of age, and 6-9 years of age [79], [80]. Malathion dicarboxylic acid levels above LOD were associated with a 2.24-fold increase in the number of abnormal reflexes in the infants. Higher levels of total DEAP and total DAP were associated with an increase in abnormal reflexes in the infants, as was total DMAP after paraoxonase expression was considered [79]. Prenatal maternal DAP was associated with a decrement in mental development at 12 months of age [80]. In later childhood, increasing prenatal DAP and DMAP were associated with decrements in perceptual reasoning in the group whose mothers carried a particular paraoxonase-1 genotype.

In contrast, however, are the results from a cohort of mothers and their offspring residing in Cincinnati [81], which found no detrimental effects of gestational exposure to OPs on neurobehavioral outcome among infants. Two urine samples were obtained from a cohort of multi-ethnic pregnant women and analyzed for DAP. Infant neurobehavior was assessed at about five weeks of age. Higher levels of creatinine-corrected DEAP were associated with improved attention and reduced lethargy and hypotonia. Higher levels of creatinine-corrected DAP were associated with fewer signs of autonomic stress. Women who were white, married, had advanced education, and reported more frequent consumption of fresh fruits and vegetables had higher concentrations of OP metabolites during pregnancy. 
Our study has many strengths. Its design was longitudinal, and the same participants were followed over three agricultural seasons encompassing a full year. All urine samples were first morning voids, which have been found to be the best predictor of weighted-average daily metabolite concentration [82]. In addition, the participants contributed three urine samples over a five-day period (days 1, 3 and 5); our analysis used the geometric means of the DAP metabolites detected in the three samples, thereby reducing the day-to-day variability of the subjects' measurements. House dust and urine samples were collected during three different intervals in a single agricultural year and therefore reflect the annual cycle of OP use in the orchards. The urine and dust samples reflect dimethyl OP usage especially well, as the collection intervals coincided with regular dimethyl OP application in spring/summer OP application, reduced application during autumn, and cessation in early winter. All of the adult farmworkers were employed in pome fruit orchards and thus they were exposed to similar types of OPs.

A limitation to this study is that exact OP usage during the harvest season can be difficult to determine, as application times vary according to the specific fruit variety. Different apple varieties ripen at different times during the harvest season, and late-ripening orchards may receive OP applications on a different schedule than early-ripening orchards. Another limitation is that the seasonal application of chlorpyrifos was initiated after most of the non-spray-season urine and dust samples had been collected. Therefore the urine and dust samples are less reflective of diethyl OP exposure from chlorpyrifos than they are of dimethyl OP and diazinon exposure, since the dimethyl OP and diazinon applications occurred simultaneous 
with the sample collection intervals. This may explain why chlorpyrifos and DEP+DETP metabolites were detected at low levels in the samples even though chlorpyrifos was applied in significant quantities in the Valley in 2005-06. A third limitation is that DAPs were not measured in the house dust samples. A more complete picture of the relationship between pesticide-contaminated house dust and urinary pesticide metabolites could be obtained if concentrations of both intact OPs and OP breakdown products were known.

A potential confounding factor in the dust observations could include home pesticide use. Of the five OP pesticides found most abundantly in the house dust samples, only one of the five - diazinon - was available to consumers for home use at the time the samples were taken. Regression analysis of the total DEP+DETP urinary metabolites (nmol/mL) vs. diazinon residues in house dust (nmol/g) showed no significant association for either adults or children.

In conclusion, we found significant seasonal and occupational associations between urinary OP metabolite levels and intact OP residues in house dust among this cohort of farmworker and non-farmworker adults and children. We found higher concentrations of OP residues in the households and vehicles of the farmworker families than the non-farmworker families, and higher concentrations of OP metabolites in the urine of the farmworker families. Results of our regression analysis indicate that there is a significant positive association between the concentration of dimethyl OPs in household dust and the concentration of dimethyl OP metabolites in urine, most notably during thinning season, when dimethyl OPs 
are applied regularly, but also during harvest season when OP's are applied less frequently. When parental occupation was included in the regression model as an independent variable, results indicated that both parental occupation and concentration of OP residues in household dust influenced the concentration of urinary dimethyl OP metabolites. This demonstrates that farmworkers who are occupationally exposed to OPs are transporting OPs into their vehicles and then into their homes, creating a take-home pathway by which young children are exposed to agricultural OPs. 


\section{FUTURE DIRECTIONS}

It is possible that stronger correlations between children's urinary OP metabolites and OP residues in house dust would become apparent if the individual DAPs in the dust samples are measured and included in the regression model. A model including both intact OPs and the DAPs resulting from environmental breakdown would give a more complete picture of young children's exposure to OPs. Although the dust samples are still available, a re-analysis of OP breakdown products as well as intact OPs would need to be performed.

Analysis shows that there is less DMP and more DMTP in the urine of the FW cohort compared to the NFW cohort; this observation holds true for both the adults and the children. This could be an artifact of sample storage, or it could reflect differences in exposure or in OP metabolism. DMP is formed when the dimethyl OPs are metabolized to the oxon form, which acts as an inhibitor of acetylcholinesterase [83]. Zachariah Guerrette has proposed that DMTP may also be formed when azinphos-methyl is metabolized to the oxon form [84]. Further statistical analysis of the urinary metabolites is warranted.

Dust and urine samples were also analyzed for other substances such as phthalates and heavy metals; further statistical analysis using that data could lead to a more complete picture of the children's exposures to environmental contaminants. 
[1] United States Department of Agriculture Washington Field Office, "2006 Washington Annual Agriculture Bulletin," 2006.

[2] United States Department of Agriculture, "Department of Agricuture National Agricultural Statistics Service, Agricultural Statistics 2006," 2006.

[3] United States Congress, "TITLE I - SUSPENSION - APPLICATORS Subtitle A Suspension," Congressional Register, no. 2, pp. 1489-1538, 1996.

[4] United States Environmental Protection Agency, "Implementing the Food Quality Protection Act Progress Report : Implementing FQPA," 1999.

[5] United States Environmental Protection Agency, "Human Health Risk Assessment Chlorpyrifos," 2000.

[6] United States Environmental Protection Agency, "Interim Reregistration Eligibility Decision for Chlorpyrifos," 2002.

[7] United States Environmental Protection Agency, "Interim Reregistration Eligibility Decision for Azinphos-Methyl," 2001.

[8] United States Environmental Protection Agency, "Interim Reregistration Eligibility Decision for Phosmet," 2001.

[9] United States Environmental Protection Agency, "Interim Reregistration Eligibility Decision for Diazinon," 2004.

[10] G. P. Thelin and W. W. Stone, "Estimation of annual agricultural pesticide use for counties of the conterminous United States, 1992-2009: Scientific investigation report 2013-5009, U.S. Geological Survey Scientific Investigations Report," 2013.

[11] W. W. Stone, "Estimated Annual Agricultural Pesticide Use for Counties of the Conterminous United States, 1992-2009," U.S. Geological Survey Data Series 752, p. 1-p. pamphlet, 14 tables, 2013.

[12] L. G. Costa, "Toxic Effects of Pesticides." In: Klaassen DC, editor. Casarett and Doull's Toxicology: The Basic Science of Poisons. Boston: McGraw-Hill; 8th edition, 2013. pp. 933-81.

[13] C. N. Pope, "Central Nervous System Effects and Neurotoxicity." In: Gupta, R.C., editor. Toxicology of Organophosphate \& Carbamate Compounds. Elsevier Academic Press, 2006. pp 271-292.

[14] A. C. Povey, R. McNamee, H. Alhamwi, S. J. Stocks, G. Watkins, A. Burns, and R. Agius, "Pesticide exposure and screen-positive neuropsychiatric disease in British sheep farmers," Environ. Res., vol. 135, pp. 262-270, 2014.

[15] M. Bayrami, T. Hashemi, A. A. Malekirad, H. Ashayeri, F. Faraji, and M. Abdollahi, "Electroencephalogram, cognitive state, psychological disorders, clinical symptom, and oxidative stress in horticulture farmers exposed to organophosphate pesticides," Toxicol. Ind. Health, vol. 28, no. 1, pp. 90-96, 2012.

[16] K. M. Hayden, M. C. Norton, D. Darcey, T. Ostbye, P. P. Zandi, J. C. S. Breitner, and K. A. Welsh-Bohmer, "Occupational exposure to pesticides increases the risk of incident AD: the Cache County study," Neurology, vol. 74, no. 19, pp. 1524-30, 2010. 
[17] A. Pilkington, D. Buchanan, G. A. Jamal, R. Gillham, S. Hansen, M. Kidd, J. F. Hurley, and C. A. Soutar, "An epidemiological study of the relations between exposure to organophosphate pesticides and indices of chronic peripheral neuropathy and neuropsychological abnormalities in sheep farmers and dippers," Occup. Environ. Med., vol. 58, no. 11, pp. 702-710, 2001.

[18] N. Fiedler, H. Kiepen, K. Kelly-McNeil, and R. Fenske, "Long Term Use of Organophosphates and Neuropsychological Performance," Am. J. Ind. Med., vol. 32E, pp. 487-496, 1997.

[19] L. L. Strong, B. Thompson, G. D. Coronado, W. C. Griffith, E. M. Vigoren, and I. Islas, "Health symptoms and exposure to organophosphate pesticides in farmworkers," Am. J. Ind. Med., vol. 46, no. 6, pp. 599-606, 2004.

[20] N. J. Simcox, J. Camp, D. Kalman, A. Stebbins, G. Bellamy, I. C. Lee, and R. Fenske, "Farmworker exposure to organophosphorus pesticide residues during apple thinning in central Washington State," Am. Ind. Hyg. Assoc. J., vol. 60, no. 6, pp. 752-61, 1999.

[21] B. Thompson, G. D. Coronado, J. E. Grossman, K. Puschel, C. C. Solomon, I. Islas, C. L. Curl, J. H. Shirai, J. C. Kissel, and R. A. Fenske, "Pesticide take-home pathway among children of agricultural workers: Study design, methods, and baseline findings," J. Occup. Environ. Med., vol. 45, no. 1, pp. 42-53, 2003.

[22] B. Thompson, W. C. Griffith, D. B. Barr, G. D. Coronado, E. M. Vigoren, and E. M. Faustman, "Variability in the take-home pathway: farmworkers and nonfarmworkers and their children," J. Expo. Sci. Environ. Epidemiol., vol. 24, no. 5, pp. 522-31, 2014.

[23] R. A. Fenske, C. Lu, M. Negrete, and K. Galvin, "Breaking the take home pesticide exposure pathway for agricultural families: Workplace predictors of residential contamination," Am. J. Ind. Med., vol. 56, no. 9, pp. 1063-1071, 2013.

[24] C. L. Curl, R. A. Fenske, J. C. Kissel, J. H. Shirai, T. F. Moate, W. Griffith, G. Coronado, and B. Thompson, "Evaluation of take-home organophosphorus pesticide exposure among agricultural workers and their children," Environ. Health Perspect., vol. 110, no. 12, pp. 787-792, 2002.

[25] National Academy of Sciences (NAS), Pesticides in the Diets of Infants and Children. 1993.

[26] P. J. Landrigan and L. R. Goldman, "Protecting Children From Pesticides and Other Toxic Chemicals," J. Expo. Sci. Environ. Epidemiol., vol. 21, no. 2, pp. 11920, 2011.

[27] E. M. Faustman, S. M. Silbernagel, R. A. Fenske, T. M. Burbacher, and R. A. Ponce, "Mechanisms Underlying Children's Susceptibility to Environmental Toxicants," Environ. Heal., vol. 108, no. March, pp. 13-21, 2000.

[28] J. R. Roberts, C. J. Karr, and Council on Environmental Health, "Pesticide Exposure in Children," Pediatrics, vol. 130, no. 6, pp. e1765-e1788, 2012. 
[29] S. M. Engel, A. Bradman, M. S. Wolff, V. A. Rauh, K. G. Harley, J. H. Yang, L. A. Hoepner, D. B. Barr, K. Yolton, M. G. Vedar, Y. Xu, R. W. Hornung, J. G. Wetmur, J. Chen, N. T. Holland, F. P. Perera, R. M. Whyatt, B. P. Lanphear, and B. Eskenazi, "Prenatal Organophosphorus Pesticide Exposure and Child Neurodevelopment at 24 Months: An Analysis of Four Birth Cohorts," Environ. Health Perspect., November 2014.

[30] M. F. Bouchard, D. C. Bellinger, R. O. Wright, and M. G. Weisskopf, "AttentionDeficit/Hyperactivity Disorder and Urinary Metabolites of Organophosphate Pesticides," Pediatrics, vol. 125, no. 6, pp. e1270-e1277, 2010.

[31] B. Thompson, G. D. Coronado, E. M. Vigoren, W. C. Griffith, R. A. Fenske, J. C. Kissel, J. H. Shirai, and E. M. Faustman, "Para ninos saludables: a community intervention trial to reduce organophosphate pesticide exposure in children of farmworkers," Environ. Health Perspect., vol. 116, no. 5, pp. 687-694, 2008.

[32] G. D. Coronado, E. M. Vigoren, B. Thompson, W. C. Griffith, and E. M. Faustman, "Organophosphate pesticide exposure and work in pome fruit: Evidence for the take-home pesticide pathway," Environ. Health Perspect., vol. 114, no. 7, pp. 999-1006, 2006.

[33] G. D. Coronado, E. M. Vigoren, W. C. Griffith, E. M. Faustman, and B. Thompson, "Organophosphate Pesticide Exposure Among Pome and Non-Pome Farmworkers: A Subgroup Analysis of a Community Randomized Trial," J. Occup. Environ. Med., pp. 500-509, 2009.

[34] G. D. Coronado, S. Holte, E. Vigoren, W. C. Griffith, D. B. Barr, E. Faustman, and B. Thompson, "Organophosphate pesticide exposure and residential proximity to nearby fields: evidence for the drift pathway," J. Occup. Environ. Med., vol. 53, no. 8, pp. 884-91, 2011.

[35] United States Department of Agriculture, "Washington Tree Fruit Survey 2006."

[36] United States Department of Commerce, "Profiles of General Demographic Characteristics: 2000 Census of Population and Housing," 2001.

[37] United States Department of Commerce, "Profiles of General Demographic Characteristics: 2010 Census of Population and Housing," 2012.

[38] B. Thompson, G. Coronado, K. Puschel, and E. Allen, "Identifying constituents to participate in a project to control pesticide exposure in children of farmworkers," Environ. Health Perspect., vol. 109, no. Supplement 3 June, pp. 443-8, 2001.

[39] J. F. Brunner, W. Jones, E. Beers, V. Gerald, J. Dunley, C. Xiao, and G. G. Grove, "A Decade of Pesticide Use and IPM Practices in Washington's Apple Orchards," WSU Tree Fruit Research Extension Center, notice 205, 2003.

[40] J. F. Brunner, K. R. Granger, and M. D. Doerr, "Implementing OP-Alternative Pest Management Programs in Washington Apple," WSU Tree Fruit Research Extension Center, notice posted online, pp. 1-11, 2007. 
[41] R. Bravo, L. M. Caltabiano, G. Weerasekera, R. D. Whitehead, C. Fernandez, L. L. Needham, A. Bradman, and D. B. Barr, "Measurement of dialkyl phosphate metabolites of organophosphorus pesticides in human urine using lyophilization with gas chromatography-tandem mass spectrometry and isotope dilution quantification," J. Expo. Anal. Environ. Epidemiol., vol. 14, pp. 249-259, 2004.

[42] M. J. Coye, J. A. Lowe, and K. J. Maddy, "Biological monitoring of agricultural workers exposed to pesticides II. Monitoring of Intact Pesticides and Their Metabolites," J. Occup. Med., vol. 28, no. 8, pp. 628-636, 1986.

[43] D. B. Barr, L. C. Wilder, S. P. Caudill, A. J. Gonzalez, L. L. Needham, and J. L. Pirkle, "Urinary creatinine concentrations in the U.S. population: implications for urinary biologic monitoring measurements," Environ. Health Perspect., vol. 113, no. 2, pp. 192-200, 2005.

[44] G. D. Coronado, W. C. Griffith, E. M. Vigoren, and E. M. Faustman, "Where's the Dust? Characterizing Locations of Azinphos-Methyl Residues in House and Vehicle Dust Among Farmworkers with Young Children," J. Environ. Occup. Hyg., vol. 7, no. 12, pp. 663-671, 2011.

[45] T. F. Moate, M. Furia, C. Curl, J. F. Muniz, J. Yu, and R. A. Fenske, "Size exclusion chromatographic cleanup for GC/MS Determination of Organophosphorus Pesticide Residues in Household and Vehicle Dust," J. AOAC Int., vol. 85, no. 1, pp. 36-43, 2002.

[46] R Core Team 2016, "R: A language and environment for statistical computing. R Foundation for Statistical Computing, Vienna, Austria."

[47] W. Griffith, C. L. Curl, R. A. Fenske, C. A. Lu, E. M. Vigoren, and E. M. Faustman, "Organophosphate pesticide metabolite levels in pre-school children in an agricultural community: within- and between-child variability in a longitudinal study," Environ. Res., vol. 111, no. 6, pp. 751-6, 2011.

[48] D. Lunn, C. Jackson, N. Best, A. Thomas, and D. Spiegelhalter, The BUGS Book: A Practical Introduction to Bayesian Analysis. Chapman and Hall/CRC, 2012.

[49] D. J. Lunn, A. Thomas, N. Best, and D. Spiegelhalter, "WinBUGS - A Bayesian modelling framework: Concepts, structure, and extensibility," Stat. Comput., vol. 10, pp. 325-337, 2000.

[50] D. B. Barr, R. Bravo, G. Weerasekera, L. M. Caltabiano, R. D. Whitehead, A. O. Olsson, S. P. Caudill, S. E. Schober, J. L. Pirkle, E. J. Sampson, R. J. Jackson, and L. L. Needham, "Concentrations of dialkyl phosphate metabolites of organophosphorus pesticides in the U.S. population," Environ. Health Perspect., vol. 112, no. 2, pp. 186-200, 2004.

[51] Washington State University Extension, 2008 Crop Protection Guide for Tree Fruits in Washington. 2008.

[52] World Health Organization (WHO), Organophosphorus Insecticides: A General Introduction. World Health Organization, New York, NY. 1986.

[53] N. D. Forsberg, R. Rodriguez-Proteau, L. Ma, J. M. Christensen, C. S. Maier, J. J. Jenkings, and K. A. Anderson, "Organophosphorus pesticide degradation product in vitro metabolic stability and time-course uptake and elimination in rats following oral and intravenous dosing," Xenobiotica, vol. 41, no. 5, pp. 422-429, 2011. 
[54] C. Timchalk, A. Busby, J. A. Campbell, L. L. Needham, and D. B. Barr, "Comparative pharmacokinetics of the organophosphorus insecticide chlorpyrifos and its major metabolites diethylphosphate, diethylthiophosphate and 3,5,6-trichloro-2-pyridinol in the rat," Toxicology, vol. 237, no. 1-3, pp. 145-157, 2007.

[55] D. B. Barr, "Biomonitoring of exposure to pesticides," J. Chem. Heal. Saf., vol. 15, no. 6, pp. 20-29, 2008.

[56] L. Quiros-Alcala, A. Bradman, K. Smith, G. Weerasekera, M. Odetodun, D. B. Barr, M. Nishioka, R. Castorina, A. E. Hubbard, M. Nicas, H. S. Katherine, T. E. McKone, and B. B. Eskenazi, "Organophosphorus pesticide breakdown products in house dust and children's urine," J. Expo. Sci. Environ. Epidemiol., vol. 22, no. 6, pp. 559-568, 2012.

[57] W. E. Lambert, M. Lasarev, J. Muniz, J. Scherer, J. Rothlein, J. Santana, and L. McCauley, "Variation in organophosphate pesticide metabolites in urine of children living in agricultural communities," Environ. Health Perspect., vol. 113, no. 4, pp. 504-508, 2005.

[58] P. Grandjean, "Pesticide Exposure and Stunting as Independent Predictors of Neurobehavioral Deficits in Ecuadorian School Children," Pediatrics, vol. 117, no. 3, pp. e546-e556, 2006.

[59] P. Sánchez Lizardi, M. K. O’Rourke, and R. J. Morris, "The effects of organophosphate pesticide exposure on Hispanic children's cognitive and behavioral functioning," J. Pediatr. Psychol., vol. 33, no. 1, pp. 91-101, 2008.

[60] Department of Health and Human Services and Centers for Disease Control and Prevention, "Fourth National Report on Human Exposure to Environmental Chemicals, Updated Tables, September 2013," 2013.

[61] United States Environmental Protection Agency, Exposure Factors Handbook, 2011 Edition (Final). U.S. Environmental Protection Agency, Washington, DC, EPA/600/R-09/052F, 2011.

[62] R. A. Fenske, J. C. Kissel, C. Lu, D. A. Kalman, N. J. Simcox, E. H. Allen, and M. C. Keifer, "Biologically based pesticide dose estimates for children in an agricultural community," Environ. Health Perspect., vol. 108, no. 6, pp. 515-20, 2000.

[63] California Air Resources Board, "Study of Children's Activity Patterns. Final Report Under Contract No. A733-149," Sacramento, CA, 1991.

[64] J. Xue, V. Zartarian, J. Moya, N. Freeman, P. Beamer, K. Black, N. Tulve, and S. Shalat, “A Meta-Analysis of Children's Hand-to-Mouth Frequency Data for Estimating Nondietary Ingestion Exposure," Risk Anal., vol. 27, no. 2, pp. 411420, 2007.

[65] J. Xue, V. Zartarian, N. Tulve, J. Moya, N. Freeman, W. Auyeung, and P. Beamer, "A meta-analysis of children's object-to-mouth frequency data for estimating non-dietary ingestion exposure," J. Expo. Sci. Environ. Epidemiol., vol. 20, no. 6, pp. 536-545, 2010.

[66] K. Black, S. L. Shalat, N. C. G. Freeman, M. Jimenez, K. C. Donnelly, and J. A. Calvin, "Children's mouthing and food-handling behavior in an agricultural community on the US/Mexico border," J. Expo. Anal. Environ. Epidemiol., vol. 15, no. 3, pp. 244-251, 2005. 
[67] C. A. Rohrer, T. E. Hieber, L. J. Melnyk, and M. R. Berry, "Transfer efficiencies of pesticides from household flooring surfaces to foods," J. Expo. Anal. Environ. Epidemiol., vol. 13, no. 6, pp. 454-64, 2003.

[68] L. Quirós-Alcalá, A. Bradman, M. Nishioka, M. E. Harnly, A. Hubbard, T. E. McKone, J. Ferber, and B. Eskenazi, "Pesticides in house dust from urban and farmworker households in California: an observational measurement study," Environ. Health, vol. 10, no. 1, p. 19, 2011.

[69] L. Chen, T. F. Zhao, C. P. Pan, J. H. Ross, and R. I. Krieger, "Preformed biomarkers including dialkylphosphates (DAPs) in produce may confound biomonitoring in pesticide exposure and risk assessment," J. Agric. Food Chem., vol. 60, no. 36, pp. 9342-9351, 2012.

[70] D. S. Rohlman, T. A. Arcury, S. A. Quandt, M. Lasarev, J. Rothlein, R. Travers, A. Tamulinas, J. Scherer, J. Early, A. Marín, J. Phillips, and L. McCauley, "Neurobehavioral Performance in Preschool Children from Agricultural and Non-Agricultural Communities in Oregon and North Carolina," Neurotoxicology, vol. 26, no. 4, pp. 589-598, 2005.

[71] Y. Oulhote and M. F. Bouchard, "Urinary metabolites of organophosphate and pyrethroid pesticides and behavioral problems in Canadian children," Environ. Health Perspect., vol. 121, no. 11-12, pp. 1378-1384, 2013.

[72] A. R. Marks, K. Harley, A. Bradman, K. Kogut, D. B. Barr, C. Johnson, N. Calderon, and B. Eskenazi, "Organophosphate Pesticide Exposure and Attention in Young Mexican-American Children: The CHAMACOS Study," Environ. Health Perspect., vol. 118, no. 12, pp. 1768-1774, 2010.

[73] J. G. Young, B. Eskenazi, E. A. Gladstone, A. Bradman, L. Pedersen, C. Johnson, D. B. Barr, C. E. Furlong, and N. T. Holland, "Association between in utero organophosphate pesticide exposure and abnormal reflexes in neonates," Neurotoxicology, vol. 26, no. 2, pp. 199-209, 2005.

[74] M. F. Bouchard, J. Chevrier, K. G. Harley, K. Kogut, M. Vedar, N. Calderon, C. Trujillo, C. Johnson, A. Bradman, D. B. Barr, and B. Eskenazi, "Prenatal exposure to organophosphate pesticides and IQ in 7-year-old children," Environ. Health Perspect., vol. 119, no. 8, pp. 1189-1195, 2011.

[75] F. P. Perera, V. Rauh, W. Y. Tsai, P. Kinney, D. Camann, D. Barr, T. Bernert, R. Garfinkel, Y. H. Tu, D. Diaz, J. Dietrich, and R. M. Whyatt, "Effects of transplacental exposure to environmental pollutants on birth outcomes in a multiethnic population," Environ. Health Perspect., vol. 111, no. 2, pp. 201205, 2003.

[76] V. A. Rauh, R. Garfinkel, F. P. Perera, H. F. Andrews, L. Hoepner, D. B. Barr, R. Whitehead, D. Tang, and R. W. Whyatt, "Impact of prenatal chlorpyrifos exposure on neurodevelopment in the first 3 years of life among inner-city children," Pediatrics, vol. 118, no. 6, pp. e1845-59, 2006.

[77] V. Rauh, S. Arunajadai, M. Horton, F. Perera, L. Hoepner, D. B. Barr, and R. Whyatt, "Seven-year neurodevelopmental scores and prenatal exposure to chlorpyrifos, a common agricultural pesticide," Environ. Health Perspect., vol. 119, no. 8, pp. 1196-1201, 2011. 
[78] G. S. Berkowitz, J. Obel, E. Deych, R. Lapinski, J. Godbold, Z. Liu, P. J. Landrigan, and M. S. Wolff, "Exposure to indoor pesticides during pregnancy in a multiethnic, urban cohort," Environ. Health Perspect., vol. 111, no. 1, pp. 7984, 2003.

[79] S. M. Engel, G. S. Berkowitz, D. B. Barr, S. L. Teitelbaum, J. Siskind, S. J. Meisel, J. G. Wetmur, and M. S. Wolff, "Prenatal organophosphate metabolite and organochlorine levels and performance on the Brazelton Neonatal Behavioral Assessment Scale in a multiethnic pregnancy cohort," Am. J. Epidemiol., vol. 165, no. 12, pp. 1397-1404, 2007.

[80] S. M. Engel, J. Wetmur, J. Chen, C. Zhu, D. B. Barr, R. L. Canfield, and M. S. Wolff, "Prenatal exposure to organophosphates, paraoxonase 1, and cognitive development in childhood," Environ. Health Perspect., vol. 119, no. 8, pp. 1182-1188, 2011.

[81] K. Yolton, Y. Xu, H. Sucharew, P. Succop, M. Altaye, A. Popelar, M. A. Montesano, A. M. Calafat, and J. C. Khoury, "Impact of low-level gestational exposure to organophosphate pesticides on neurobehavior in early infancy: a prospective study," Environ. Health, vol. 12, no. 1, p. 79, 2013.

[82] J. C. Kissel, C. L. Curl, G. Kedan, C. Lu, W. Griffith, D. B. Barr, L. L. Needham, and R. A. Fenske, "Comparison of organophosphorus pesticide metabolite levels in single and multiple daily urine samples collected from preschool children in Washington State," J. Expo. Anal. Environ. Epidemiol., vol. 15, no. 2, pp. 164$171,2005$.

[83] D. L. Sudakin and D. L. Stone, "Dialkyl phosphates as biomarkers of organophosphates: The current divide between epidemiology and clinical toxicology," Clin. Toxicol., vol. 49, no. 9, pp. 771-781, 2011.

[84] Z. N. Guerrette, "Integrating Biomarkers of Organophosphate Pesticides in an Agriculturally Exposed Population," Diss. University of Washington, 2012. 
Table 1. Estimated annual agricultural pesticide use in metric tons for Benton and Yakima counties following the methods described in Thelin and Stone (2013). U.S. Department of Agriculture countylevel data for harvested-crop acreage were used in conjunction with proprietary Crop Reporting District-level pesticide-use data to estimate county-level pesticide use. Estimated pesticide use (EPest) values were calculated with both the EPest-high and EPest-low methods.

\begin{tabular}{|c|c|c|c|c|c|c|}
\hline & \multicolumn{6}{|c|}{ Estimate $(1,000 \mathrm{~kg})$} \\
\hline & \multicolumn{3}{|c|}{2006} & \multicolumn{3}{|c|}{2005} \\
\hline & Benton & Yakima & Total & Benton & Yakima & Total \\
\hline Azinphos-methyl & 14.0 & 68.5 & 82.5 & 15.5 & 70.4 & 85.9 \\
\hline Malathion & $0.5-1.2$ & $1.0-1.2$ & $1.5-2.4$ & $1.5-1.6$ & 3.3 & $4.8-4.9$ \\
\hline Phosmet & 0.7 & 5.4 & 6.2 & 5.9 & 33.3 & 39.4 \\
\hline Chlorpyrifos & $11.9-12.3$ & $49.3-49.5$ & $61.2-61.8$ & $13.8-14.6$ & $52.4-52.6$ & $66.2-67.2$ \\
\hline Diazinon & $0.7-1.7$ & $2.1-2.2$ & $2.8-3.9$ & $0.4-0.5$ & $0.8-0.9$ & $1.2-1.4$ \\
\hline
\end{tabular}

Thelin, G.P., and Stone, W.W., 2013, Estimation of annual agricultural pesticide use for counties of the conterminous United States, 1992-2009: U.S. Geological Survey. Scientific Investigations Report 2013-5009, 54 p. 


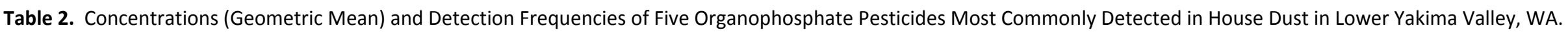

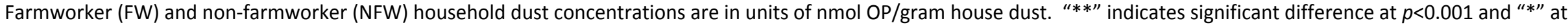
$p<0.05$ between FW and NFW, based on Welch two-sample t-tests.

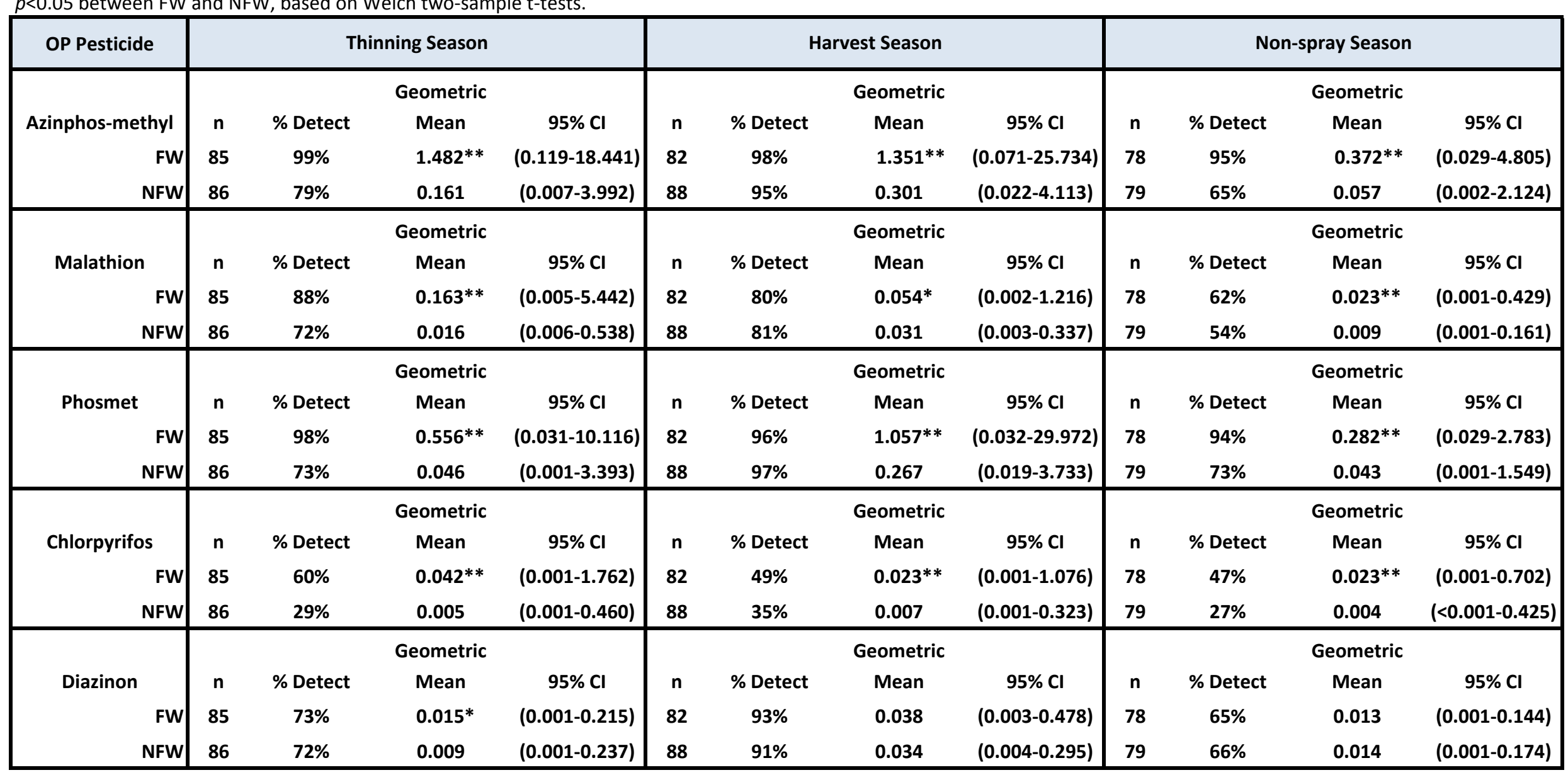


Table 3. Concentrations (Geometric Mean) and Detection Frequencies of Five Organophosphate Pesticides Most Commonly Detected in Vehicle Dust in Lower Yakima Valley, WA. Farmworker (FW) and non-farmworker (NFW) vehicle dust concentrations are in units of nmol OP/ gram house dust. "**" indicates significant difference at $p<0.001$ and "*" at $p<0.05$ between FW and NFW, based on Welch two-sample t-tests.

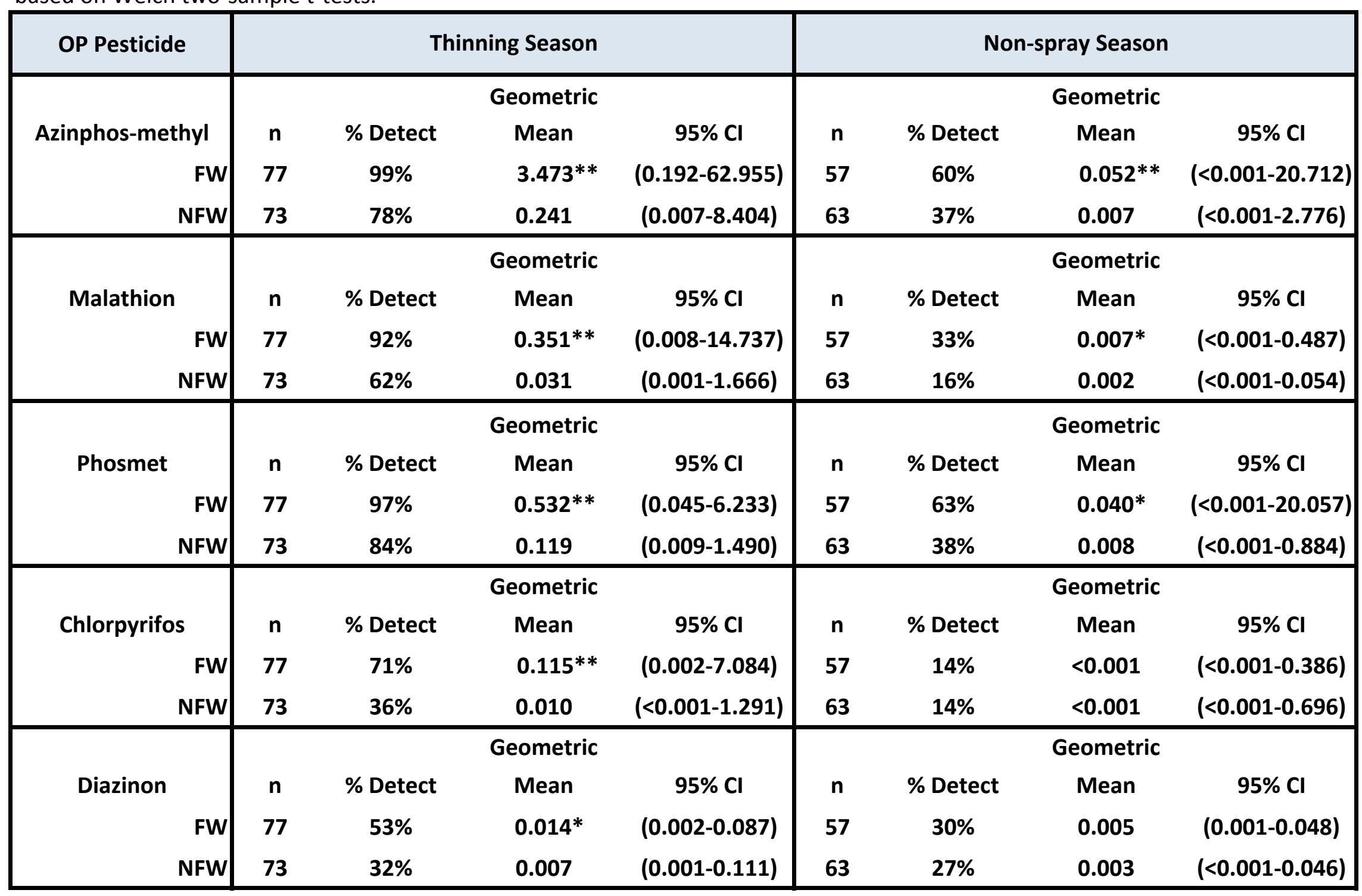


Table 4A. Concentrations (Geometric Mean) and Detection Frequencies of Six Dialkylphosphate (DAP) Metabolites Detected in Child Urine in Lower Yakima Valley, WA. Farmworker (FW) and non-farmworker (NFW) urinary metabolite concentrations are in units of nmol DAP/milliliter urine. " **" indicates significant difference at $p<0.001$ and “*” at $p<0.05$ between FW and NFW, based on Welch two-sample t-tests.

\begin{tabular}{|c|c|c|c|c|c|c|c|c|c|c|c|c|}
\hline Urinary Metabolite & \multicolumn{4}{|c|}{ Thinning Season } & \multicolumn{4}{|c|}{ Harvest Season } & \multicolumn{4}{|c|}{ Non-Spray Season } \\
\hline \multirow{4}{*}{ DMAP } & \multicolumn{4}{|c|}{ Geometric } & \multicolumn{4}{|c|}{ Geometric } & \multicolumn{4}{|c|}{ Geometric } \\
\hline & $\mathrm{n}$ & \% Detect & Mean & $95 \% \mathrm{Cl}$ & $\mathrm{n}$ & \% Detect & Mean & $95 \% \mathrm{Cl}$ & $\mathrm{n}$ & $\%$ Detect & Mean & $95 \% \mathrm{Cl}$ \\
\hline & -- & -- & $0.205^{* *}$ & $(0.034-1.235)$ & -- & -- & 0.244 & $(0.029-2.074)$ & -- & -- & 0.083 & $(0.012-0.556)$ \\
\hline & -- & -- & 0.102 & $(0.011-0.908)$ & -- & -- & 0.220 & $(0.021-2.355)$ & -- & -- & 0.108 & $(0.019-0.616)$ \\
\hline \multirow{4}{*}{ DMP } & \multicolumn{4}{|c|}{ Geometric } & \multicolumn{4}{|c|}{ Geometric } & \multicolumn{4}{|c|}{ Geometric } \\
\hline & $\mathrm{n}$ & \% Detect & Mean & $95 \% \mathrm{Cl}$ & $\mathrm{n}$ & \% Detect & Mean & $95 \% \mathrm{Cl}$ & $\mathrm{n}$ & \% Detect & Mean & $95 \% \mathrm{Cl}$ \\
\hline & 85 & $96 \%$ & $0.042^{*}$ & $(0.004-0.417)$ & 82 & $94 \%$ & 0.029 & $(0.002-0.492)$ & 78 & $83 \%$ & 0.016 & $(0.001-0.206)$ \\
\hline & 85 & $98 \%$ & 0.029 & $(0.003-0.266)$ & 88 & $92 \%$ & 0.042 & $(0.002-0.730)$ & 78 & $94 \%$ & $0.030^{*}$ & $(0.003-0.320)$ \\
\hline \multirow{4}{*}{ DMTP } & \multicolumn{4}{|c|}{ Geometric } & \multicolumn{4}{|c|}{ Geometric } & \multicolumn{4}{|c|}{ Geometric } \\
\hline & $\mathbf{n}$ & $\%$ Detect & Mean & $95 \% \mathrm{Cl}$ & $\mathbf{n}$ & \% Detect & Mean & $95 \% \mathrm{Cl}$ & $\mathrm{n}$ & $\%$ Detect & Mean & $95 \% \mathrm{Cl}$ \\
\hline & 85 & $100 \%$ & $0.114 * *$ & $(0.017-0.764)$ & 82 & $100 \%$ & $0.161^{* *}$ & $(0.016-1.667)$ & 78 & $100 \%$ & 0.041 & $(0.005-0.342)$ \\
\hline & 85 & $100 \%$ & 0.049 & $(0.004-0.606)$ & 88 & $100 \%$ & 0.122 & $(0.011-1.398)$ & 78 & $99 \%$ & 0.047 & $(0.005-0.430)$ \\
\hline \multirow{4}{*}{ DMDTP } & \multicolumn{4}{|c|}{ Geometric } & \multicolumn{4}{|c|}{ Geometric } & \multicolumn{4}{|c|}{ Geometric } \\
\hline & $n$ & $\%$ Detect & Mean & $95 \% \mathrm{Cl}$ & $\mathbf{n}$ & \% Detect & Mean & $95 \% \mathrm{Cl}$ & $\mathrm{n}$ & \% Detect & Mean & $95 \% \mathrm{Cl}$ \\
\hline & 85 & $100 \%$ & $0.015^{* *}$ & $(0.002-0.131)$ & 82 & $89 \%$ & 0.007 & $(<0.001-0.244)$ & 78 & $90 \%$ & 0.004 & $(<0.001-0.047)$ \\
\hline & 85 & $98 \%$ & 0.005 & $(0.001-0.050)$ & 88 & $98 \%$ & $0.017^{*}$ & $(0.001-0.353)$ & 78 & $97 \%$ & 0.005 & $(0.001-0.040)$ \\
\hline \multirow{4}{*}{ DEP+DETP } & \multicolumn{4}{|c|}{ Geometric } & \multicolumn{4}{|c|}{ Geometric } & \multicolumn{4}{|c|}{ Geometric } \\
\hline & $\mathbf{n}$ & \% Detect & Mean & $95 \% \mathrm{Cl}$ & $\mathbf{n}$ & \% Detect & Mean & $95 \% \mathrm{Cl}$ & $\mathbf{n}$ & \% Detect & Mean & $95 \% \mathrm{Cl}$ \\
\hline & -- & -- & 0.025 & $(0.004-0.157)$ & -- & -- & 0.011 & $(0.001-0.158)$ & -- & -- & 0.014 & $(0.001-0.142)$ \\
\hline & -- & -- & 0.024 & $(0.004-0.161)$ & -- & -- & $0.023^{* *}$ & $(0.004-0.144)$ & -- & -- & $0.026 * *$ & $(0.004-0.163)$ \\
\hline \multirow{4}{*}{ DEP } & \multicolumn{4}{|c|}{ Geometric } & & & eometric & & & & eometric & \\
\hline & $\mathrm{n}$ & \% Detect & Mean & $95 \% \mathrm{Cl}$ & $\mathrm{n}$ & \% Detect & Mean & $95 \% \mathrm{Cl}$ & $\mathrm{n}$ & \% Detect & Mean & $95 \% \mathrm{Cl}$ \\
\hline & 85 & $94 \%$ & 0.013 & $(0.001-0.203)$ & 82 & $57 \%$ & 0.004 & $(<0.001-0.134)$ & 78 & $64 \%$ & 0.004 & $(<0.001-0.116)$ \\
\hline & 85 & $98 \%$ & 0.014 & $(0.001-0.194)$ & 88 & $81 \%$ & $0.008^{*}$ & $(<0.001-0.178)$ & 78 & $92 \%$ & $0.014 * *$ & $(0.001-0.225)$ \\
\hline & & & Seometric & & & & eometric & & & & eometric & \\
\hline DETP & $\mathbf{n}$ & \% Detect & Mean & $95 \% \mathrm{Cl}$ & $\mathbf{n}$ & \% Detect & Mean & $95 \% \mathrm{Cl}$ & $\mathbf{n}$ & \% Detect & Mean & $95 \% \mathrm{Cl}$ \\
\hline $\mathrm{FW}$ & 85 & $98 \%$ & 0.004 & $(0.001-0.026)$ & 82 & $66 \%$ & 0.002 & $(<0.001-0.036)$ & 78 & $91 \%$ & 0.004 & $(<0.001-0.050)$ \\
\hline NFW & 85 & $96 \%$ & 0.004 & $(0.001-0.025)$ & 88 & $97 \%$ & $0.006^{* *}$ & $(0.001-0.049)$ & 78 & $99 \%$ & 0.004 & $(0.001-0.026)$ \\
\hline DEDTP & & & Seometric & & & & eometric & & & & eometric & \\
\hline (not used in calculations) & $\mathbf{n}$ & \% Detect & Mean & $95 \% \mathrm{Cl}$ & $\mathbf{n}$ & \% Detect & Mean & $95 \% \mathrm{Cl}$ & $\mathbf{n}$ & $\%$ Detect & Mean & $95 \% \mathrm{Cl}$ \\
\hline $\mathrm{FW}$ & 85 & $79 \%$ & 0.001 & $(<0.001-0.008)$ & 82 & $39 \%$ & 0.001 & $(<0.001-0.003)$ & 78 & $49 \%$ & $0.001 *$ & $(<0.001-0.006)$ \\
\hline NFW & 85 & $92 \%$ & 0.001 & $(<0.001-0.004)$ & 88 & $73 \%$ & $0.001 * *$ & $(<0.001-0.008)$ & 78 & $86 \%$ & 0.001 & $(<0.001-0.005)$ \\
\hline
\end{tabular}


Table 4B. Concentrations (Geometric Mean) and Detection Frequencies of Six Dialkylphosphate (DAP) Metabolites Detected in Adult Urine in Lower Yakima Valley, WA. Farmworker (FW) and non-farmworker (NFW) urinary metabolite concentrations are in units of nmol DAP/milliliter urine. "**" indicates significant difference at $p<0.001$ and "*" at $p<0.05$ between FW and NFW, based on Welch two-sample t-tests.

\begin{tabular}{|c|c|c|c|c|c|c|c|c|c|c|c|c|}
\hline Urinary Metabolite & \multicolumn{4}{|c|}{ Thinning Season } & \multicolumn{4}{|c|}{ Harvest Season } & \multicolumn{4}{|c|}{ Non-Spray Season } \\
\hline \multirow{4}{*}{ DMAP } & & & Geometric & & & & Geometric & & & & jeometric & \\
\hline & $\mathbf{n}$ & \% Detect & Mean & $95 \% \mathrm{Cl}$ & n & \% Detect & Mean & $95 \% \mathrm{Cl}$ & $\mathbf{n}$ & \% Detect & Mean & $95 \% \mathrm{Cl}$ \\
\hline & -- & -- & $0.647^{* *}$ & $(0.046-9.086)$ & -- & -- & $0.666 * *$ & $(0.035-12.628)$ & -- & -- & 0.083 & $(0.014-0.491)$ \\
\hline & -- & -- & 0.078 & $(0.018-0.346)$ & -- & -- & 0.240 & $(0.013-4.369)$ & -- & -- & 0.087 & $(0.020-0.389)$ \\
\hline \multirow{4}{*}{ DMP } & & & Geometric & & & & Geometric & & & & jeometric & \\
\hline & $\mathrm{n}$ & \% Detect & Mean & $95 \% \mathrm{Cl}$ & $\mathrm{n}$ & \% Detect & Mean & $95 \% \mathrm{Cl}$ & $\mathrm{n}$ & \% Detect & Mean & $95 \% \mathrm{Cl}$ \\
\hline & 85 & $98 \%$ & $0.113 * *$ & $(0.009-1.478)$ & 82 & $98 \%$ & $0.072 *$ & $(0.002-2.298)$ & 78 & $73 \%$ & 0.012 & $(0.001-0.176)$ \\
\hline & 86 & $97 \%$ & 0.021 & $(0.003-0.141)$ & 88 & $91 \%$ & 0.045 & $(0.002-0.930)$ & 78 & $95 \%$ & $0.025 * *$ & $(0.003-0.227)$ \\
\hline \multirow{4}{*}{ DMTP } & & & Geometric & & & & Geometric & & & & jeometric & \\
\hline & $\mathbf{n}$ & \% Detect & Mean & $95 \% \mathrm{Cl}$ & $\mathbf{n}$ & $\%$ Detect & Mean & $95 \% \mathrm{Cl}$ & $\mathbf{n}$ & \% Detect & Mean & $95 \% \mathrm{Cl}$ \\
\hline & 85 & $100 \%$ & $0.413^{* *}$ & $(0.022-7.676)$ & 82 & $100 \%$ & $0.468 * *$ & $(0.022-9.928)$ & 78 & $100 \%$ & 0.048 & $(0.008-0.295)$ \\
\hline & 86 & $100 \%$ & 0.036 & $(0.006-0.223)$ & 88 & $100 \%$ & 0.129 & $(0.005-3.466)$ & 79 & $100 \%$ & 0.040 & $(0.006-0.245)$ \\
\hline \multirow{4}{*}{ DMDTP } & & & Geometric & & & & Geometric & & & & jeometric & \\
\hline & $n$ & \% Detect & Mean & $95 \% \mathrm{Cl}$ & $\mathrm{n}$ & $\%$ Detect & Mean & $95 \% \mathrm{Cl}$ & $\mathbf{n}$ & \% Detect & Mean & $95 \% \mathrm{Cl}$ \\
\hline & 85 & $100 \%$ & $0.040 * *$ & $(0.003-0.550)$ & 82 & $90 \%$ & 0.022 & $(<0.001-1.750)$ & 78 & $95 \%$ & 0.004 & $(<0.001-0.042)$ \\
\hline & 86 & $100 \%$ & 0.005 & $(0.001-0.027)$ & 88 & $98 \%$ & 0.020 & $(0.001-0.602)$ & 79 & $97 \%$ & 0.004 & $(0.001-0.024)$ \\
\hline \multirow{4}{*}{ DEP+DETP } & & & Geometric & & & & Geometric & & & & jeometric & \\
\hline & $\mathbf{n}$ & \% Detect & Mean & $95 \% \mathrm{Cl}$ & $n$ & $\%$ Detect & Mean & $95 \% \mathrm{Cl}$ & $\mathbf{n}$ & $\%$ Detect & Mean & $95 \% \mathrm{Cl}$ \\
\hline & -- & -- & 0.026 & $(0.004-0.167)$ & -- & -- & 0.014 & $(0.001-0.200)$ & -- & -- & 0.013 & $(0.002-0.100)$ \\
\hline & - & -- & 0.021 & $(0.004-0.118)$ & -- & -- & 0.020 & $(0.002-0.237)$ & -- & -- & $0.023 * *$ & (0.004-0.154) \\
\hline \multirow{4}{*}{ DEP } & & & Geometric & & & & Geometric & & & & jeometric & \\
\hline & $n$ & \% Detect & Mean & $95 \% \mathrm{Cl}$ & $n$ & \% Detect & Mean & $95 \% \mathrm{Cl}$ & $\mathrm{n}$ & \% Detect & Mean & $95 \% \mathrm{Cl}$ \\
\hline & 85 & $93 \%$ & 0.012 & $(0.001-0.189)$ & 82 & $63 \%$ & 0.004 & $(<0.001-0.169)$ & 78 & $64 \%$ & 0.004 & $(<0.001-0.076)$ \\
\hline & 86 & $93 \%$ & 0.011 & $(0.001-0.170)$ & 88 & $74 \%$ & 0.007 & $(<0.001-0.256)$ & 79 & $86 \%$ & $0.011^{* *}$ & (0.001-0.220) \\
\hline \multirow{4}{*}{ DETP } & & & Geometric & & & & Geometric & & & & jeometric & \\
\hline & $n$ & $\%$ Detect & Mean & $95 \% \mathrm{Cl}$ & $\mathrm{n}$ & $\%$ Detect & Mean & $95 \% \mathrm{Cl}$ & $\mathbf{n}$ & $\%$ Detect & Mean & $95 \% \mathrm{Cl}$ \\
\hline & 85 & $95 \%$ & $0.005^{*}$ & $(0.001-0.045)$ & 82 & $71 \%$ & 0.002 & $(<0.001-0.062)$ & 78 & $94 \%$ & 0.004 & $(<0.001-0.042)$ \\
\hline & 86 & $99 \%$ & 0.004 & (0.001-0.019) & 88 & $91 \%$ & $0.005^{* *}$ & $(<0.001-0.080)$ & 79 & $99 \%$ & 0.004 & $(0.001-0.026)$ \\
\hline \multirow{4}{*}{$\begin{array}{c}\text { DEDTP } \\
\text { (not used in calculations) } \\
\mathrm{FW} \\
\mathrm{NFW}\end{array}$} & & & Geometric & & & & Geometric & & & & Seometric & \\
\hline & n & \% Detect & Mean & $95 \% \mathrm{Cl}$ & n & \% Detect & Mean & $95 \% \mathrm{Cl}$ & $\mathbf{n}$ & \% Detect & Mean & $95 \% \mathrm{Cl}$ \\
\hline & 85 & $84 \%$ & 0.001 & $(<0.001-0.007)$ & 82 & $49 \%$ & 0.001 & $(<0.001-0.003)$ & 78 & $55 \%$ & 0.001 & $(<0.001-0.006)$ \\
\hline & 86 & $91 \%$ & $0.001 * *$ & $(<0.001-0.006)$ & 88 & $80 \%$ & $0.001 *$ & $(<0.001-0.011)$ & 79 & $84 \%$ & 0.001 & $(<0.001-0.007)$ \\
\hline
\end{tabular}


Table 5A. Proportions (Geometric Mean) and Detection Frequencies of Three Dimethylalkylphosphate (DMAP) Metabolites Detected in Child Urine in Lower Yakima Valley, WA.

Farmworker (FW) and non-farmworker (NFW) urinary metabolite concentrations are in units of nmol DAP/milliliter urine. "**" indicates significant difference at $p<0.001$ and "** at $p<0.05$ between FW and NFW, based on Welch two-sample t-tests.

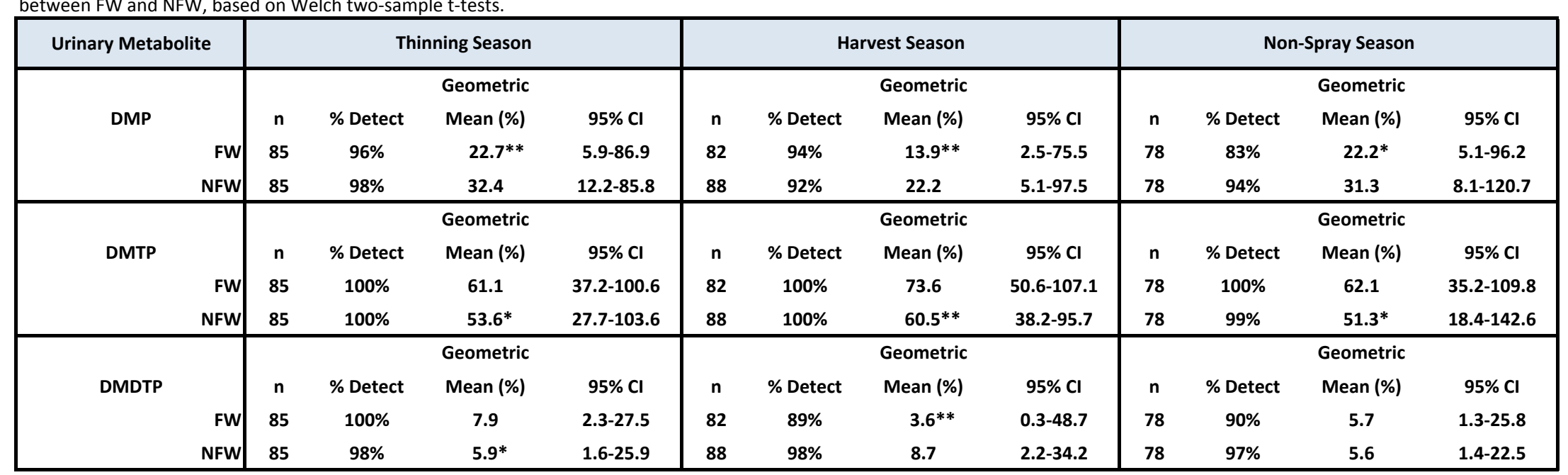


Table 5B. Proportions (Geometric Mean) and Detection Frequencies of Three Dimethylalkylphosphate (DMAP) Metabolites Detected in Adult Urine in Lower Yakima Valley, WA.

Farmworker (FW) and non-farmworker (NFW) urinary metabolite concentrations are in units of nmol DAP/milliliter urine. "**" indicates significant difference at $p<0.001$ and "** at $p<0.05$ between FW and NFW, based on Welch two-sample t-tests.

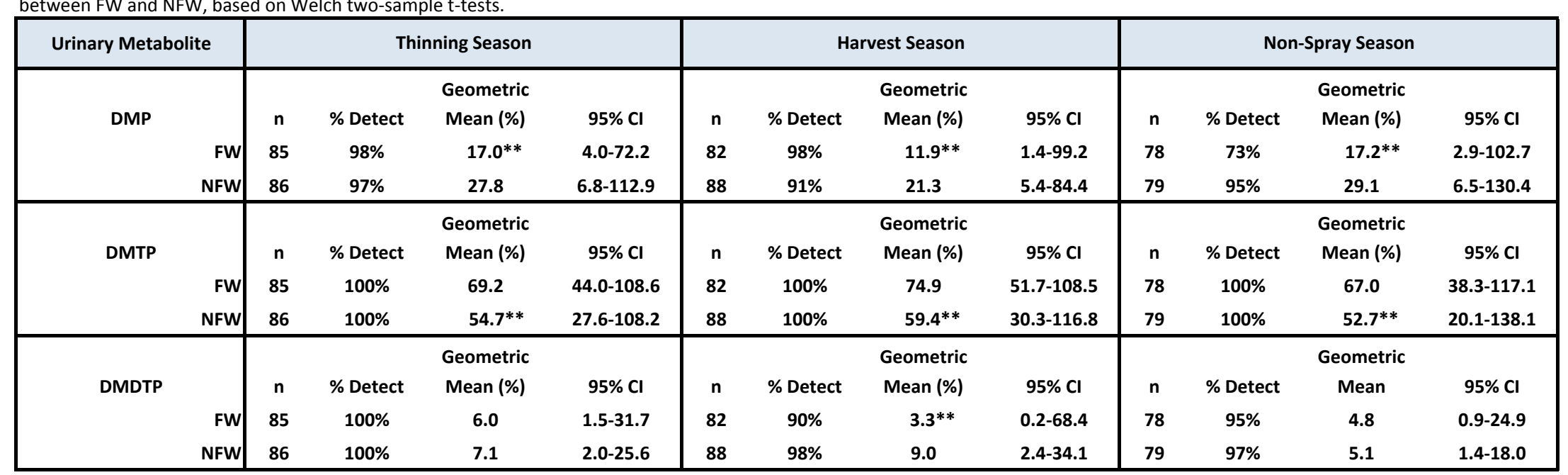


Table 6A. Concentrations (Geometric Mean) of Six Dialkylphosphate (DAP) Metabolites Detected in Child Urine in United States and Lower Yakima Valley, WA, compared to data from the

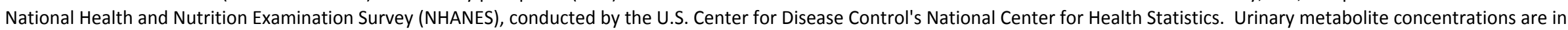
units of nmol DAP/milliliter urine, without creatinine correction.

\begin{tabular}{|c|c|c|c|c|c|c|c|c|c|c|c|}
\hline \multirow[b]{3}{*}{ OP Metabolite } & \multicolumn{5}{|c|}{ NHANES 2005-06 } & \multicolumn{6}{|c|}{ UW Center for Child Environmental Health Risks Research } \\
\hline & \multirow[b]{2}{*}{ GM } & \multirow[b]{2}{*}{$95 \% \mathrm{Cl}$} & \multicolumn{2}{|c|}{ 50th Percentile } & \multirow{2}{*}{$\begin{array}{c}\text { Sample } \\
\text { Size }\end{array}$} & \multicolumn{2}{|c|}{ Thinning } & \multicolumn{2}{|c|}{ Harvest } & \multicolumn{2}{|c|}{ Non-Spray } \\
\hline & & & GM & $95 \% \mathrm{Cl}$ & & GM & $95 \% \mathrm{Cl}$ & GM & $95 \% \mathrm{Cl}$ & GM & $95 \% \mathrm{Cl}$ \\
\hline \multicolumn{12}{|l|}{ DMP } \\
\hline Children 6-11 & \# & & $<L O D$ & & 350 & & & & & & \\
\hline FW Children 2-6 & & & & & & 0.045 & $(0.005-0.434)$ & 0.030 & $(0.002-0.455)$ & 0.016 & $(0.001-0.188)$ \\
\hline NFW Children 2-6 & & & & & & 0.030 & $(0.004-0.241)$ & 0.044 & $(0.003-0.705)$ & 0.031 & $(0.003-0.309)$ \\
\hline
\end{tabular}

\section{DMTP}

Children 6-11

$0.019 \quad(0.016-0.023)$

$0.017 \quad(0.012-0.024)$

349

FW Children 2-6

NFW Children 2-6

$\begin{array}{llllll}0.120 & (0.017-0.861) & 0.155 & (0.016-1.480) & 0.044 & (0.005-0.352) \\ 0.050 & (0.004-0.591) & 0.118 & (0.010-1.416) & 0.050 & (0.005-0.485)\end{array}$

\section{DMDTP}

Children 6-11

FW Children 2-6

$0.050 \quad(0.004-0.591)$

$0.118 \quad(0.010-1.416)$

$0.050 \quad(0.005-0.485)$

NFW Children 2-6

$0.015 \quad(0.001-0.157)$

$0.008 \quad(0.002-0.217)$

$0.004 \quad(0.001-0.047)$

$0.005 \quad(0.001-0.052)$

$0.017 \quad(0.001-0.349)$

$0.006 \quad(0.001-0.043)$

\section{DEP}

Children 6-11

\#

$<$ LOD

350

FW Children 2-6

NFW Children 2-6

$\begin{array}{lllcll}0.013 & (0.001-0.199) & 0.004 & (<0.001-0.121) & 0.004 & (0.001-0.112) \\ 0.012 & (0.001-0.200) & 0.008 & (0.001-0.156) & 0.014 & (0.001-0.212)\end{array}$

\section{DETP}

Children 6-11

FW Children 2-6

NFW Children 2-6

$<L O D$

\section{DEDTP}

Children 6-11

FW Children 2-6

NFW Children 2-6

\#

$<$ LOD

\begin{tabular}{llllll}
0.001 & $(0.001-0.007)$ & 0.001 & $(<0.001-0.004)$ & 0.001 & $(<0.001-0.005)$ \\
0.001 & $(0.001-0.004)$ & 0.001 & $(0.001-0.008)$ & 0.001 & $(0.001-0.007)$ \\
\hline
\end{tabular}

\# Geometric Mean was not calculated if the proportion of results below the limit of detection was greater than $40 \%$.

"<LOD" means less than the limit of detection, which may vary by year and by individual sample. 
Table 6B. Concentrations (Geometric Mean) of Six Dialkylphosphate (DAP) Metabolites Detected in Adult Urine in United States and Lower Yakima Valley, WA, compared to data from the

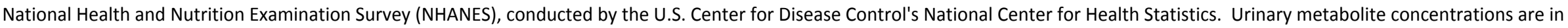
units of nmol DAP/milliliter urine, without creatinine correction.

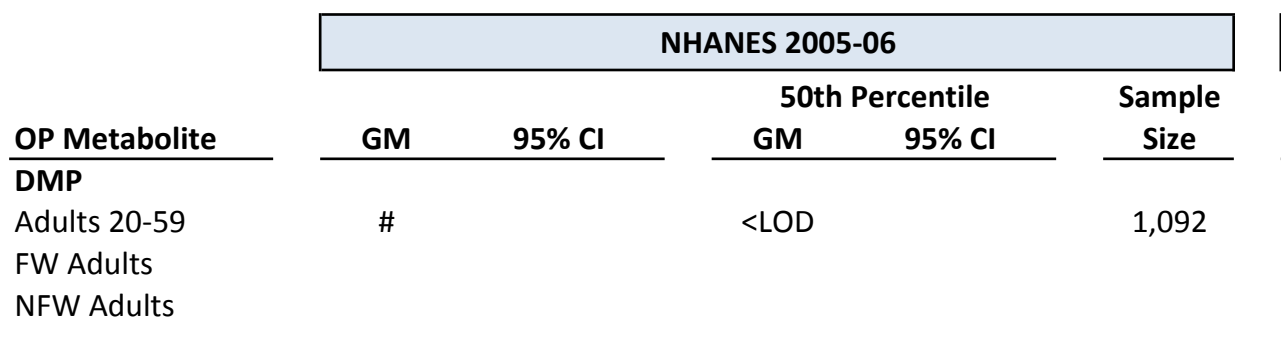

\begin{tabular}{|c|c|c|c|c|c|}
\hline \multicolumn{6}{|c|}{ UW Center for Child Environmental Health Risks Research } \\
\hline \multicolumn{2}{|c|}{ Thinning } & \multicolumn{2}{|c|}{ Harvest } & \multicolumn{2}{|c|}{ Non-Spray } \\
\hline GM & $95 \% \mathrm{Cl}$ & GM & $95 \% \mathrm{Cl}$ & GM & $95 \% \mathrm{Cl}$ \\
\hline 0.107 & $(0.008-1.492)$ & 0.075 & $(0.002-2.511)$ & 0.012 & $(0.001-0.166)$ \\
\hline 0.019 & $(0.003-0.135)$ & 0.047 & $(0.002-0.927)$ & 0.024 & $(0.003-0.215)$ \\
\hline
\end{tabular}

\section{DMTP}

Adults 20-59

FW Adults

$0.012(0.010-0.014)$

$0.010 \quad(0.009-0.012)$

1,092

NFW Adults

$0.433 \quad(0.027-7.548)$

$0.472 \quad(0.024-9.873)$

$0.048 \quad(0.008-0.289)$

$0.037 \quad(0.006-0.220)$

$0.131 \quad(0.005-3.504)$

$0.043 \quad(0.008-0.289)$

\section{DMDTP}

Adults 20-59

$<\mathrm{LOD}$

1,092

FW Adults

NFW Adults

$0.038 \quad(0.003-0.127)$

$0.005 \quad(0.003-0.133)$

0.021

0.020

$0.003 \quad(0.001-0.112)$

$0.004 \quad(0.003-0.177)$

\section{DEP}

Adults 20-59

FW Adults

NFW Adults

\#

$<$ LOD

1,092

$\begin{array}{lllcll}0.012 & (0.001-0.212) & 0.004 & (<0.001-0.163) & 0.003 & (<0.001-0.071) \\ 0.011 & (0.001-0.173) & 0.007 & (0.001-0.226) & 0.011 & (0.001-0.201)\end{array}$

\section{DETP}

Adults 20-59

FW Adults

NFW Adults

$<$ LOD

\section{DEDTP}

Adults 20-59

FW Adults

NFW Adults

\#

$<$ LOD

\begin{tabular}{llllll}
0.001 & $(0.001-0.007)$ & 0.001 & $(<0.001-0.003)$ & 0.001 & $(<0.001-0.005)$ \\
0.001 & $(0.001-0.006)$ & 0.001 & $(0.001-0.010)$ & 0.001 & $(0.001-0.008)$ \\
\hline
\end{tabular}

\# Geometric Mean was not calculated if the proportion of results below the limit of detection was greater than $40 \%$.

"<LOD" means less than the limit of detection, which may vary by year and by individual sample. 